\title{
A Review on Ultrasonic-Assisted Forming: Mechanism, Model, and Process
}

\author{
Guangda Shao, Hongwei Li ${ }^{*}$ and Mei Zhan
}

\begin{abstract}
Compared with conventional forming processes, ultrasonic-assisted forming technology with a high frequency and small amplitude can significantly improve the forming quality of materials. Owing to the advantages of reduced forming force, improved surface quality, avoidance of forming defects, and strengthened surface structure, ultrasonicassisted forming technology has been applied to increasingly advanced forming processes, such as incremental forming, spinning, and micro-forming. However, in the ultrasonic-assisted forming process, there are multiple ultrasonic mechanisms, such as the volume effect and surface effect. The explanation of the effect of ultrasonic vibration (UV) on plastic deformation remains controversial, hindering the development of related technologies. Recently, many researchers have proposed many new theories and technologies for ultrasonic-assisted forming. To summarize these developments, systematic discussions on mechanisms, theoretical models, and forming performances are provided in this review. On this basis, the limitations of the current study are discussed. In addition, an outlook for ultrasonicassisted forming is proposed: efficient and stable UV systems, difficulty forming components with complex geometry, explanation of the in-depth mechanism, a systematic theoretical prediction model, and multi-field-coupling energyassisted forming are considered to be hot spots in future studies. The present review enhances existing knowledge of ultrasonic-assisted forming, and facilitates a fast reference for related researchers.
\end{abstract}

Keywords: Ultrasonic vibration, Forming, Mechanism, Model, Processing performance

\section{Introduction}

The development of high-end equipment in industries, particularly in the aviation and aerospace industry, urgently requires the development of component forming with respect to parameters such as high performance, light weight, high precision, resource saving, and environmental friendliness. Ultrasonic-assisted forming, where the ultrasonic field is supplemented during deformation, can meet the above requirements, and has become an advanced high-energy rate forming technology.

In the ultrasonic-assisted forming process, an ultrasonic frequency vibration is applied to the blank using a forming tool. The ultrasonic amplitude is generally

*Correspondence: lihongwei@nwpu.edu.cn

Shaanxi Key Laboratory of Precision Forming Technology and Equipment, School of Materials Science and Engineering, Northwestern Polytechnical University, Xi'an 710072, China within $100 \mu \mathrm{m}$, and the vibration frequency is between $20 \mathrm{kHz}$ and $100 \mathrm{kHz}$. As shown in Figure 1, the ultrasonic-assisted forming system generally includes an ultrasonic generator, transducer, horn, and forming tool [1-3]. The ultrasonic generator converts the alternating current into a high-frequency electric-oscillation signal. The transducer converts the high-frequency electric oscillation signal into a high-frequency mechanical vibration through an inverse piezoelectric effect. The horn amplifies the ultrasonic amplitude of the transducer, and is connected to the forming tool, causing it to vibrate at a certain amplitude and frequency during the deformation.

Since the discovery of the "softening effect" by Blaha [4], where the forming force of zinc crystals is significantly reduced by superimposing ultrasonic vibration (UV) during deformation, many researchers have conducted a large number of follow-up studies. The main mechanisms of ultrasonic-assisted forming are 


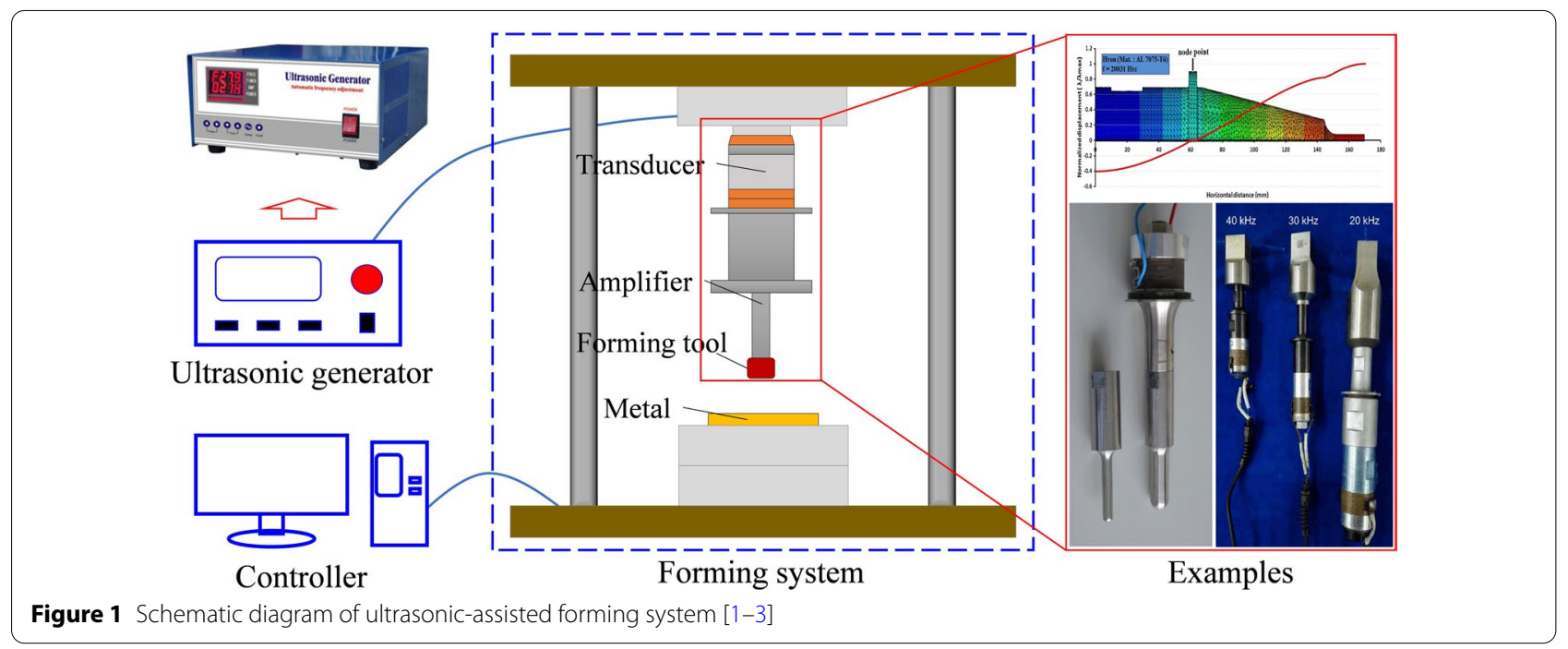

the volume effect and surface effect $[5,6]$. The volume effect refers to the phenomenon in which the material stress-strain relationship changes under the influence of UV. This phenomenon can be explained as follows: On the one hand, periodic loading and unloading in the forming process causes a stress superposition effect. On the other hand, UV produces an oscillation of the atoms, resulting in acoustic softening effect and residual effect. The surface effect refers to the phenomenon in which UV changes the micromorphology and roughness of the material surface. In addition, the friction force between the mold and blank changes $[7,8]$.

Ultrasonic-assisted forming technology has the advantages of reducing the forming force, improving the surface quality, preventing forming defects, and strengthening the surface structure. With the development of advanced technologies, such as microscopic observation and numerical simulation, there has been extensive ongoing research on the mechanism and modeling of ultrasonic-assisted forming. In addition, UV has been applied to an increasing number of advanced forming processes, such as incremental forming, spinning, and microforming [9-11]. Therefore, it is necessary to systematically summarize the latest developments in the field of ultrasonic-assisted forming and to analyze their advantages and limitations in order to facilitate fast referencing for researchers.

To this end, this paper presents a systematic review of related studies on ultrasonic-assisted forming. First, the different mechanisms of UV in the forming process are explained in detail. Second, the research progress of the theoretical models is discussed. Third, the advantages of using UV in different forming processes are discussed, and finally, future research directions related to ultrasonic-assisted forming are presented.

\section{Mechanism of Ultrasonic-Assisted Forming}

Researchers can understand the advantages of UV on the forming process by analyzing the mechanism of ultrasonic-assisted forming. Here, the current studies on the mechanism are reviewed from the perspectives of the volume effect and surface effect.

\subsection{Volume Effect}

\subsubsection{Stress Superposition Effect}

The stress superposition effect was first proposed by Nevill and Brotzen [12], who attributed the stress reduction phenomenon to the superposition effect of the stable static load and alternating vibration load. This type of superposition does not affect the microstructure of the material. As shown in Figure 2, the phenomenon of repeated elastic unloading and loading occurs when the ultrasonic horn vibrates along the loading direction. The ultrasonic horn moves in a downward direction, and the stress is reduced during the unloading stage. In contrast, the ultrasonic horn moves upwards, and the stress increases during the loading stage. Therefore, the stress-strain curve has a serrated shape. However, highfrequency dynamic force signals cannot be collected by conventional force sensors owing to their low acquisition frequency. Therefore, the actual measured stress-strain curve represents the mean stress-strain curve between the lower envelope curve and the original curve without UV.

However, the stress reduction phenomenon cannot be explained using only the stress superposition effect [13]. 


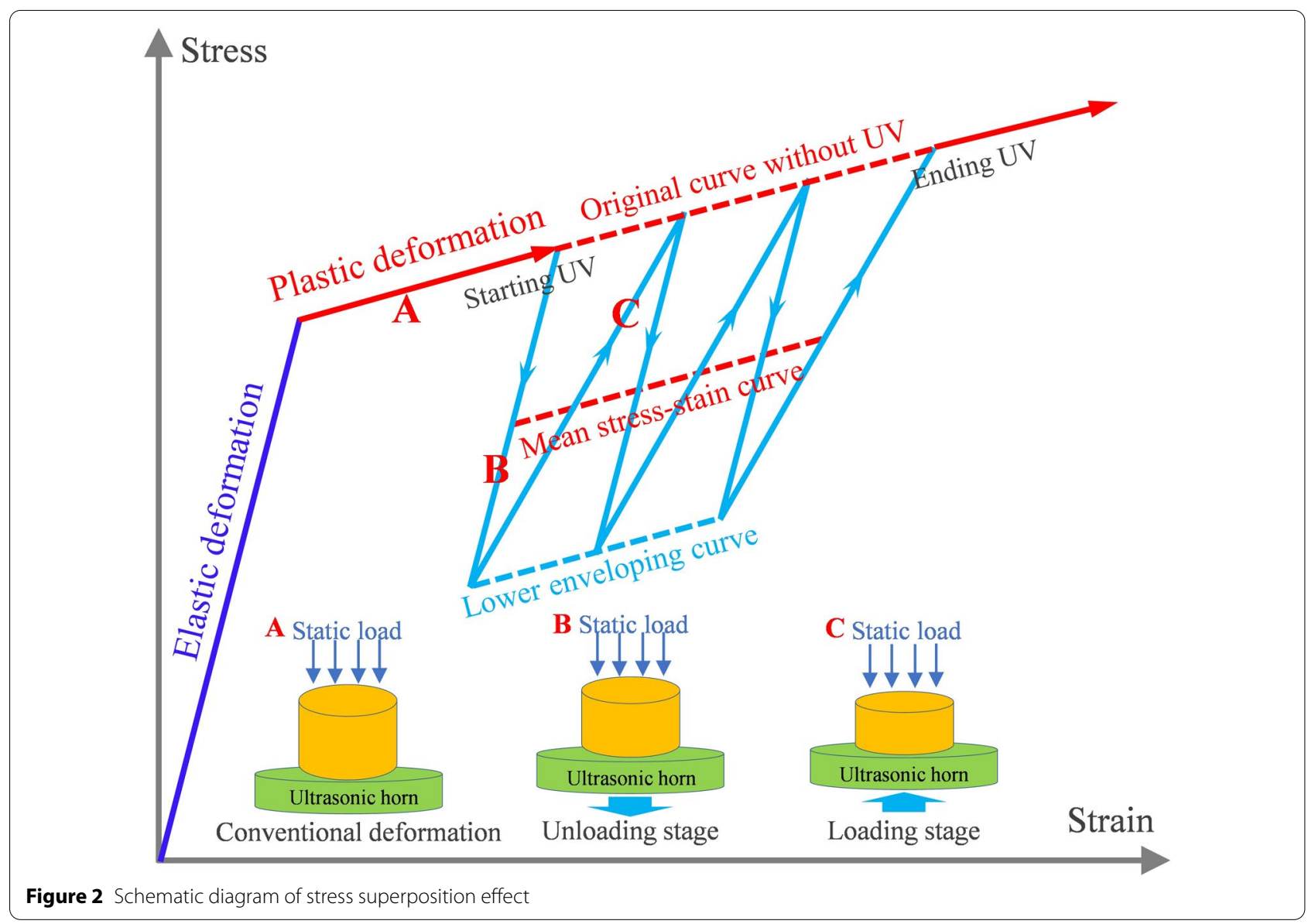

Some researchers found that the decrease in the forming force measured in the experiment was much larger than that predicted by the finite-element model. They attributed this phenomenon to a reduction in the friction force caused by the high-frequency vibration between the contact surfaces [14]. However, the stress superposition effect and friction reduction cannot fully explain the mechanism of the stress reduction phenomenon [15, 16]. Yao et al. [17] considered that the acoustic softening effect has a significant impact on the flow stress of a material. At present, researchers generally consider that the stress superposition effect dominates at low acoustic energies, while the acoustic softening effect dominates when the acoustic energy increases to a critical value [18, 19].

\subsubsection{Acoustic Softening Effect}

The acoustic softening effect refers to the phenomenon in which the application of UV during deformation influences the microstructure evolution and produces a reduction in the deformation resistance. However, this softening phenomenon disappeared immediately after the UV was stopped. When there is an acoustic softening effect, the yield strength and flow stress of the material are significantly reduced, whereas the elongation may be increased [20,21]. The reduction in the flow stress caused by the acoustic softening effect is similar to that of thermal softening, but the acoustic energy that is required to produce the same degree of softening is 107 times less than the thermal energy. Therefore, the acoustic energy utilization efficiency is higher $[4,13,22]$. A noticeable softening phenomenon occurs when UV is applied in both the elastic and plastic deformation stages for many metals, such as copper, titanium, aluminum, and steel [21, 23-26].

In the ultrasonic-assisted micro-upsetting experiment, reducing the sample size increased the acoustic energy absorbed per unit volume, and the stress reduction also increased [27]. In the ultrasonic-assisted tension experiment, the deformation was concentrated in the region near the ultrasonic source with a higher acoustic energy [24]. The above phenomenon shows that the acoustic softening effect becomes more noticeable with an increase in the acoustic energy absorbed by the material. Acoustic energy is related to the ultrasonic amplitude and frequency. Therefore, many researchers consider that the 
stress reduction is approximately linearly proportional to the amplitude [23, 25, 26]. However, there are still contradictory reports. It was found that a lower vibration frequency led to a more significant acoustic softening effect in the ultrasonic-assisted compression of aluminum and titanium [2]. In addition, the amplitude had no significant effect on the acoustic softening during the uniaxial tensile experiment of the ultrathin miniaturized TA1 foil [28].

The temperature increase during the ultrasonicassisted forming is negligible $[20,24,29,30]$; therefore, the mechanism of acoustic softening is different from thermal softening. Generally, acoustic energy is preferentially absorbed by the dislocation tangle region and grain boundary. Therefore, a noticeable change in the microstructural evolution is produced [31].

The dislocation tangle region mainly absorbs the acoustic energy through three different mechanisms: resonance, relaxation, and hysteresis $[13,32]$. To explain the influence of UV on the dislocation density, some researchers proposed the dipole annihilation theory: dislocations travel longer distances in a jerky manner in the presence of UV. Accordingly, there is a greater probability of opposite dislocation meetings and annihilation, and the dislocation density eventually decreases [33]. The dipole annihilation theory has been confirmed by several experimental results. As shown in Figure 3a, the application of UV during the tension process of DC04 steel specimens significantly reduced the dislocation density, and the dislocations were concentrated at the grain boundaries [29]. Moreover, UV gradually dissipated the dislocation tangles of the titanium foil, and the dislocations tended to be distributed in parallel along the ultrasonic propagation direction [34].

The grain boundary is affected by UV mainly from two perspectives. First, the low-angle grain boundary increased as the dislocation slip increased. The volume fraction of the sub-grains also increased (Figure 3b) [33, $35,36]$. However, the acoustic energy is preferentially absorbed by the grain boundary, and grain rotation is promoted. As a result, the low-angle grain boundary gradually transformed into a high-angle grain boundary, and the volume fraction of the sub-grain also decreased (Figure 3c) [29, 37]. Under the effect of these two mechanisms, the grain boundary evolutions of different materials exhibit different trends. Moreover, with the assistance of UV, the deformation behavior is similar to that under a high strain rate because the material continues to oscillate at an extremely high speed. Therefore, twinning occurs more easily, leading to acoustic softening $[28,30]$.

The mechanisms of UV are different for materials with different crystalline structures and stacking fault energies. For aluminum with a faced-center cubic crystalline structure, the microscopic mechanism of acoustic softening is that UV promotes dislocation slip and the interaction between dislocations and precipitates [26]. For titanium with a body-centered cubic crystalline structure, the mechanism of acoustic softening is the interaction of the dislocation slip and twin boundary activation [28]. For copper with medium stacking fault energy, the lack of dynamic recovery results in a high dislocation density and discontinuous dynamic recrystallization during ultrasonic-assisted deformation. For aluminum with a high fault energy, geometric dynamic recrystallization caused by the pinching-off of serrated grain boundaries was observed after ultrasonic-assisted deformation [38].

\subsubsection{Residual Effect}

The residual effect refers to the phenomenon in which the flow stress rises or falls during the subsequent deformation after the UV is stopped. As shown in Figure 4, different ultrasonic residual effects were observed in the aluminum and titanium samples despite the similar ultrasonic softening effect. Aluminum exhibited a residual hardening phenomenon, whereas in titanium, the initial residual hardening effect was transferred to a residual softening effect with an increase in the amplitude of the applied ultrasonic vibration.

The residual softening phenomenon appears for materials such as copper and titanium alloys [20, 23, 26, 39]. This phenomenon becomes more obvious with an increase in the amplitude and vibration duration. The dislocation density reduction, grain rotation, and misorientation reduction are considered to be the reasons for the residual softening phenomenon [24, 26]. Moreover, UV promotes the formation of deformation twinning. After the saturation of twinning, the incidence of twinning decreases with continuing deformation, and the strain hardening effect induced by deformation twinning is weakened [20,39].

On the contrary, a significant residual hardening phenomenon appears for materials such as Ti-6Al-4V alloy and 1060 aluminum [25, 39]. This phenomenon can be explained by the grain refinement caused by UV and the boundary-strengthening mechanism based on the HallPetch effect.

\subsection{Surface Effect}

The application of UV in different directions can lead to a reduction in the sliding friction force [19, 40-42]. When the direction of the UV is parallel to the sliding direction, the reduction in the sliding friction force can be explained through the vector effect. Owing to the oscillations of the tool, the direction of the sliding friction force is consistent with the direction of the forming force during part of the vibration cycle, making the 

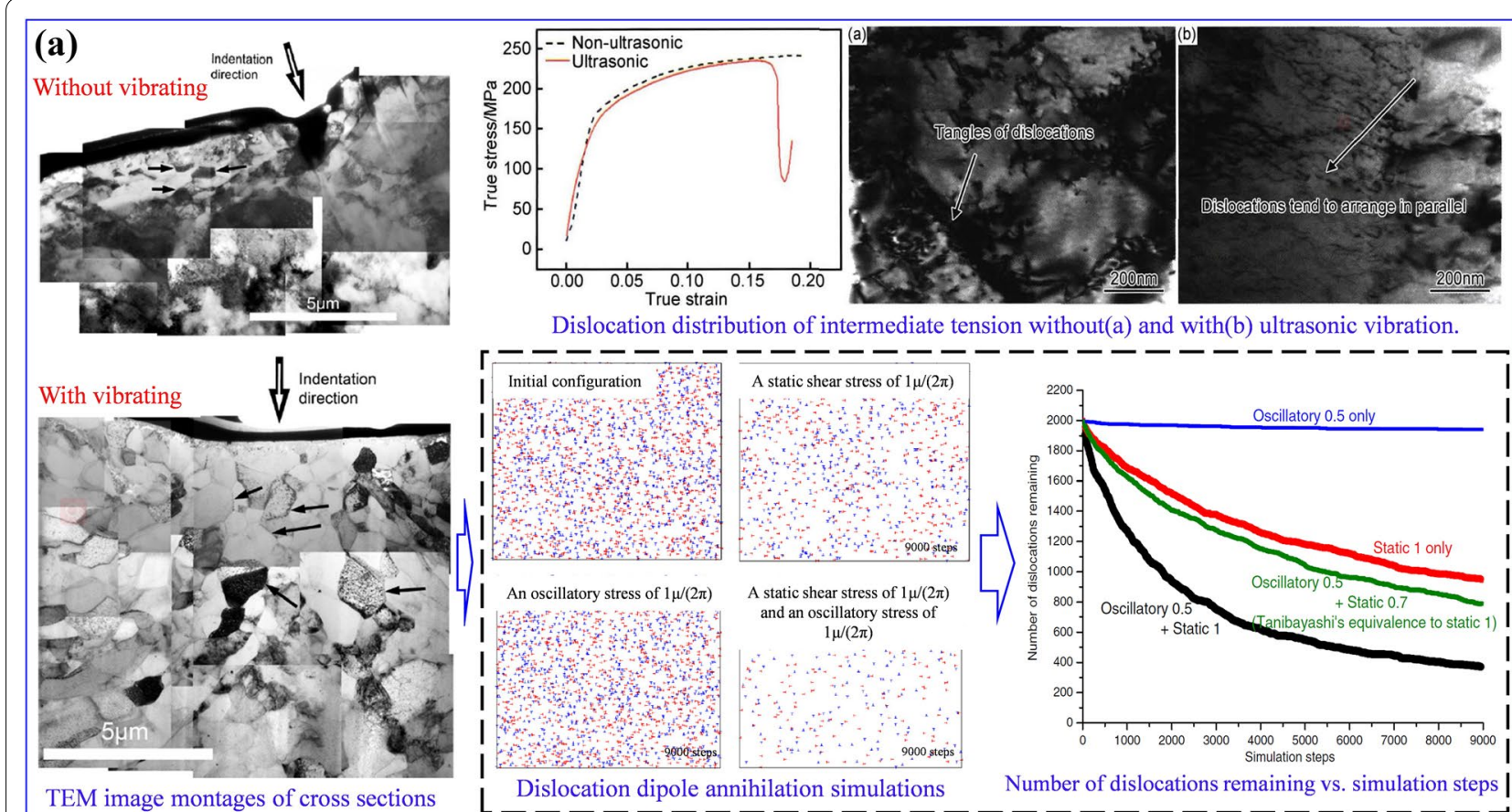

Dislocation distribution of intermediate tension without(a) and with(b) ultrasonic vibration.

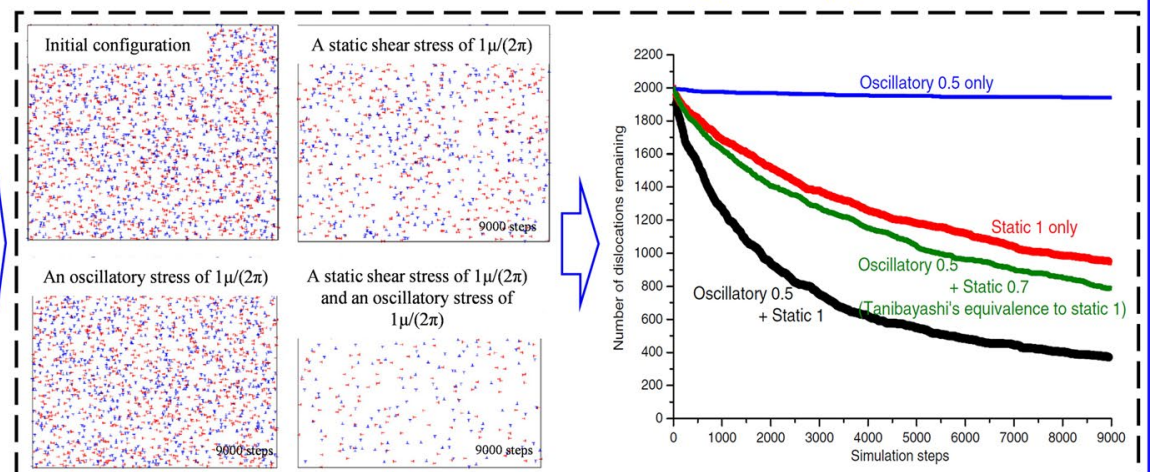

Dislocation dipole annihilation simulations

Number of dislocations remaining vs. simulation steps

\section{(b)}
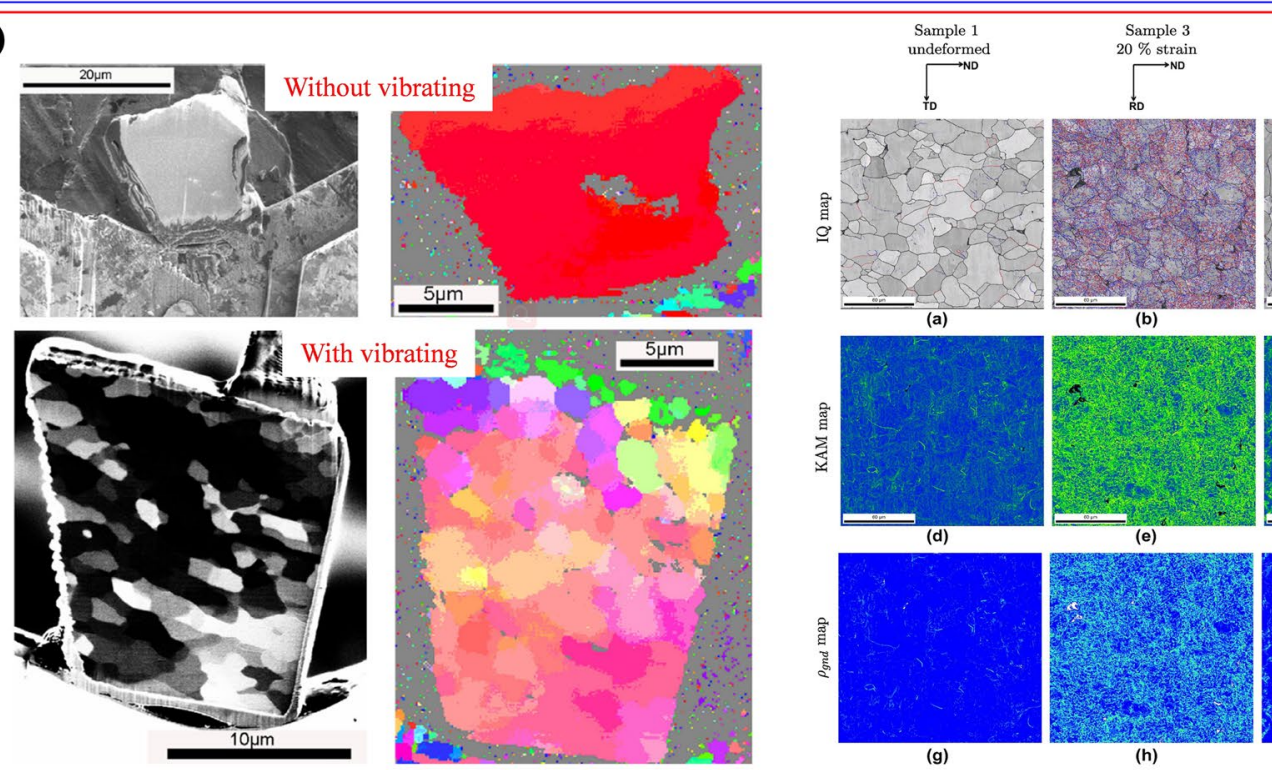

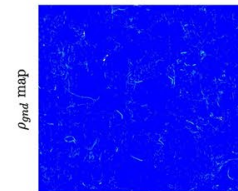

(g)

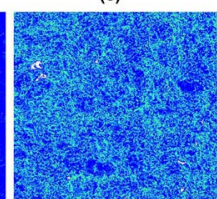

(h)
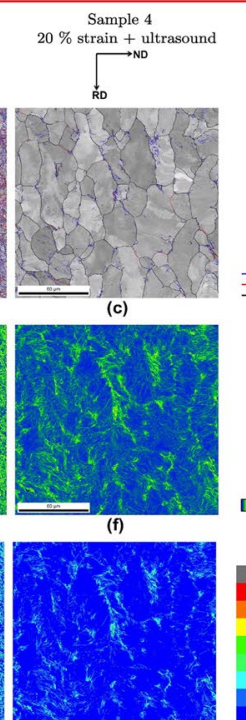

(i)

Image quality (IQ) maps of aluminum with high and low-angle grain boundaries, kernel average misorientation (KAM) map (in ${ }^{\circ}$ ) and geometrically necessary dislocation density $\left(\rho_{\text {gnd }}\right)$ maps (in $\mathrm{m}^{-2}$ ) calculated from kernel data.

Figure 3 Microscopic mechanism of acoustic softening effect: $\mathbf{a}$ the effect of UV on dislocation density, $\mathbf{b}$ the effect of UV on grain evolution [33, 34]

sliding friction force beneficial to deformation [43]. When the vibration direction is perpendicular to the sliding direction, the sliding friction force is always in the opposite direction to the resultant sliding velocity. However, the vibration of the forming tool causes an instantaneous friction force vector to present a deflection angle with the sliding direction, thereby reducing the average sliding friction force [40]. When the vibration direction is perpendicular to the contact surface, the dynamic loading decreases the average contact area between the tool and the blank. Moreover, the concave and convex parts of the contact surfaces 


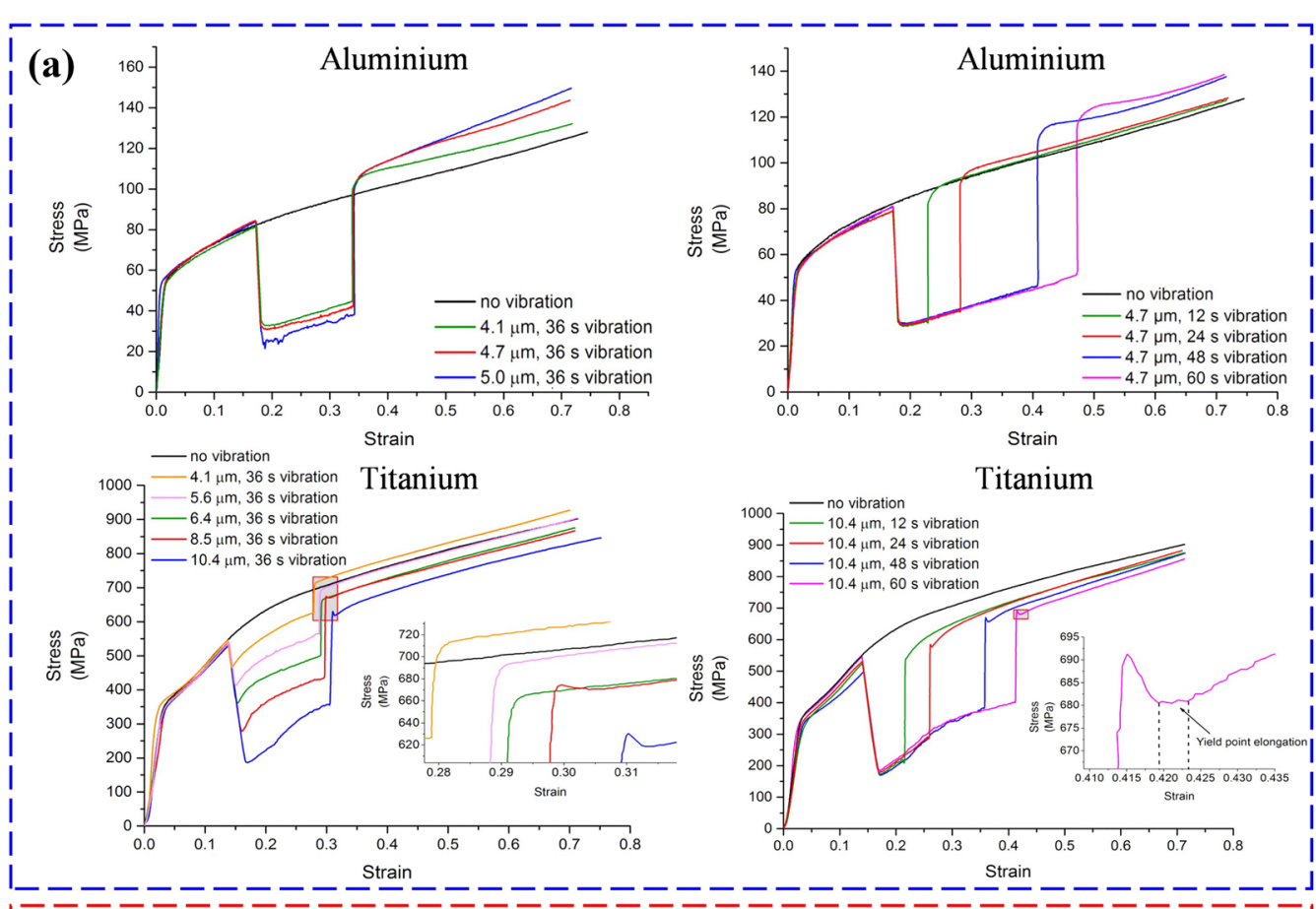

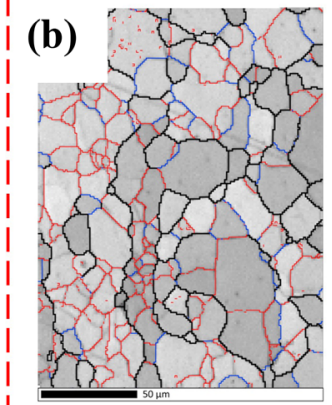

Initial material

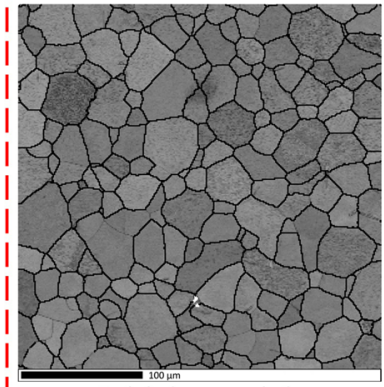

Initial material

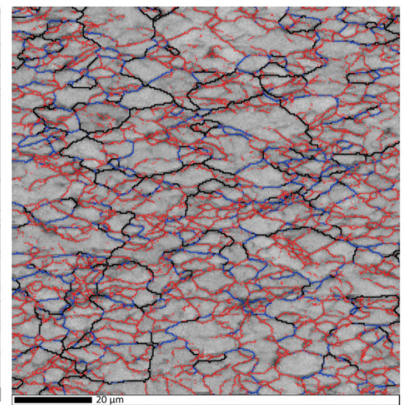

Compression sample

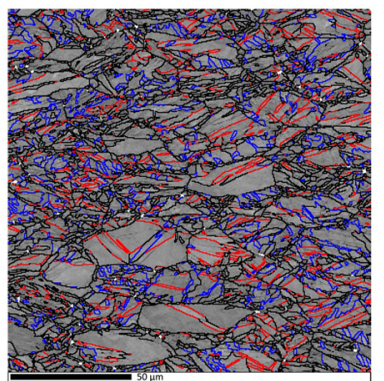

Compression sample

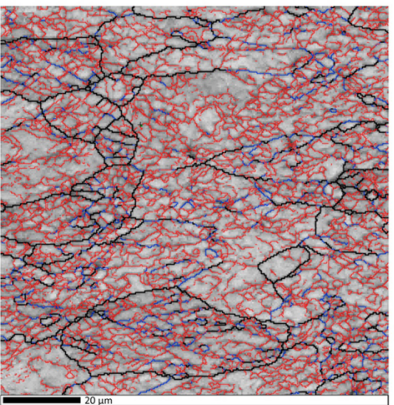

Aluminium

$-2^{\circ} \sim 10^{\circ}$ - $15^{\circ} \sim 180^{\circ}$

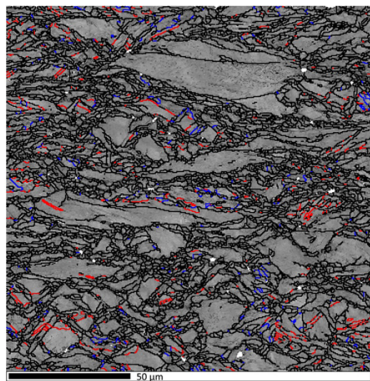

UAC material

Figure 4 Residual effect of aluminum and titanium: a residual softening and hardening effects of UV with different vibration amplitudes and different vibration durations, $\mathbf{b}$ band contrast map with grain boundaries of aluminum and titanium [39]

produce tangential deformation under UV, thereby reducing the obstacle to slip. As a result, the sliding friction force is significantly reduced $[44,45]$. As shown in Figure 5a, Cao et al. [45] performed an ultrasonicassisted sheet metal friction test, and they found that the friction coefficient decreased by approximately $40 \%$ after UV was applied.

The application of UV during the deformation process also reduced the static friction force between the relatively stationary mold and blank. By performing 

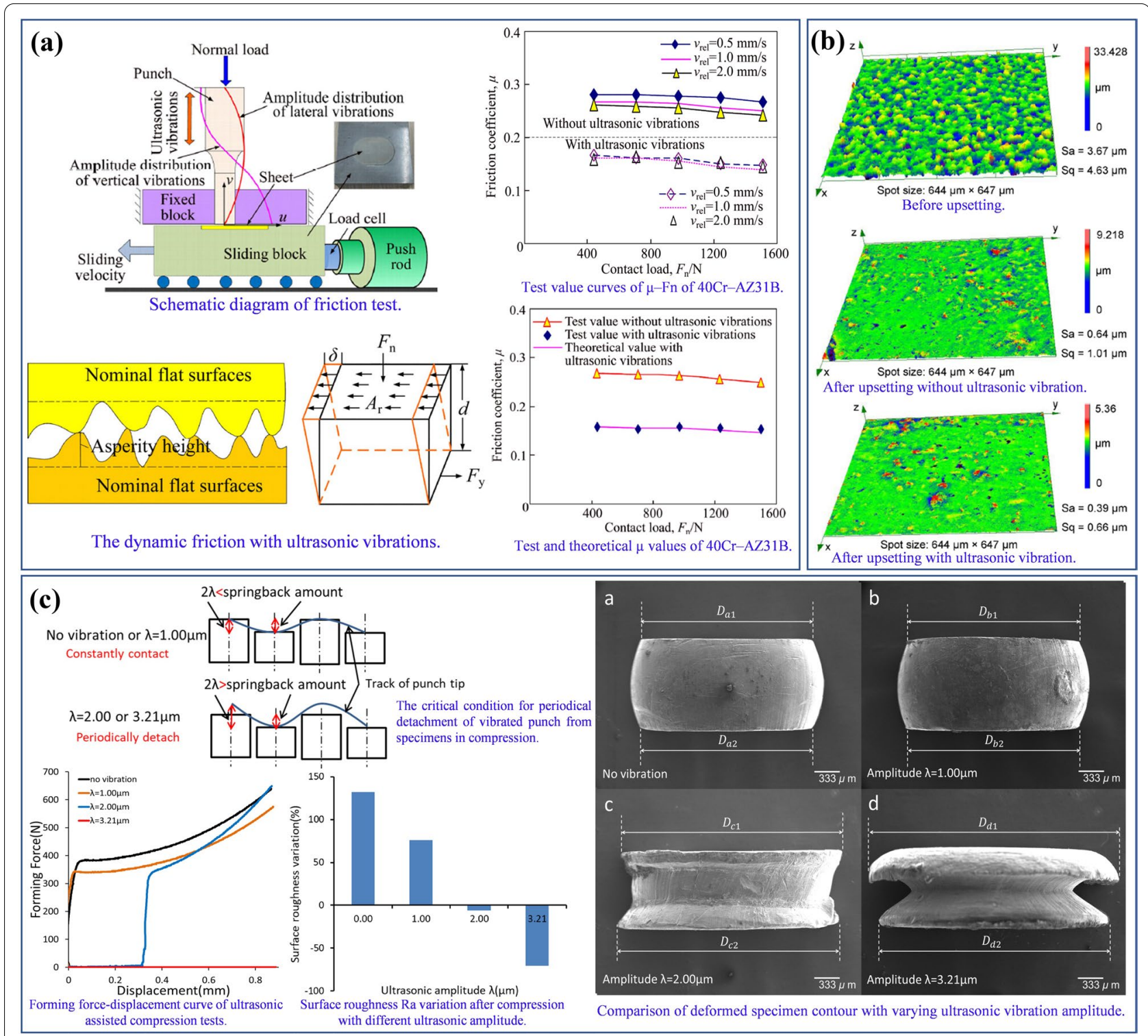

Figure 5 Surface effect of UV: a the mechanism of normal UV on friction and wear [45], $\mathbf{b}$ effect of UV on surface topography in micro-upsetting experiment of aluminum [17], c effect of ultrasonic dynamic impact during compression [53]

the upsetting test, it was found that the UV significantly reduced the friction coefficient between the sample and the tool, while the contact surface adjacent to the ultrasonic source had a more significant reduction [46-48]. In addition, the reduction in the friction coefficient increases as the sample size decreases and the amplitude increases $[16,49]$. The mechanism of UV on the static friction force mainly includes the following aspects: the micro-bulges and pits on the specimen surface reduce under the effect of UV, which diminishes the probability of occlusion with the micro-bulges and pits of the tool. The shear resistance to shear off the occlusal micro-bulges and pits was reduced. In addition, the application of UV can produce a local heating effect and reduce the local soldering between the mold/blank surfaces. Moreover, lubricants can more easily fill the contact surfaces and improve the surface lubrication conditions under the action of UV $[47,50]$.

The material flow on the surface was improved under the influence of friction reduction and local heating. Therefore, UV can significantly improve the surface quality of the sample [45]. In the ultrasonic-assisted microupsetting experiment of the aluminum, it was found that the roughness of the sample upper surface decreased 
from $1.5 \mu \mathrm{m}$ to $0.9 \mu \mathrm{m}$ after applying UV (Figure 5b) [17]. Moreover, the acoustic softening effect plays an important role in improving the surface topography. Highfrequency vibration can soften the surface asperities and promote plastic deformation, resulting in an enhancement of the surface roughness $[51,52]$.

Furthermore, when the amplitude was increased to a critical value in the ultrasonic-assisted compression experiment, the load at the initial stage of deformation dropped to zero, and the deformed sample exhibited an anti-barreling shape (Figure 5c) [53, 54]. This phenomenon cannot be explained simply by the decrease in the friction coefficient. Therefore, the concept of the ultrasonic dynamic impact effect was proposed. When the amplitude exceeds a critical value, the UV produces a high-frequency contact-detachment phenomenon between the sample and tool. Under the action of the high-frequency impact of the tool, the surface of the sample undergoes severe plastic deformation and local heating, and the surface roughness is significantly reduced [55].

\subsection{Discussion}

The explanations for the volume and surface effects are summarized in Figure 6. The volume effect can be explained by the stress superposition effect and acoustic softening effect. The stress superposition effect indicates that UV does not affect the material microstructure. During the ultrasonic-assisted forming process, the sample was subjected to repeated elastic unloading and loading. Therefore, the stress-strain curve has a serrated shape, and the actual measured stress value is reduced. However, the acoustic softening effect indicates that UV changes the material microstructure during deformation. Acoustic energy is preferentially absorbed by defects such as dislocations and grain boundaries. Therefore, the dislocation slip, grain rotation, and twinning activation are promoted, and the plastic compatibility of the material is improved. Moreover, for different materials, the acoustic softening effect has different effects on the microstructure evolution, which leads to the completely opposite phenomenon of the residual effect after stopping UV.

For the surface effect, the UV changes the contact state between the tool and the sample. Therefore, both the sliding and static friction forces are reduced. In addition, the acoustic softening effect softens the surface asperities and improves the surface roughness of the sample. Moreover, the ultrasonic dynamic impact effect occurs when the amplitude exceeds a critical value.

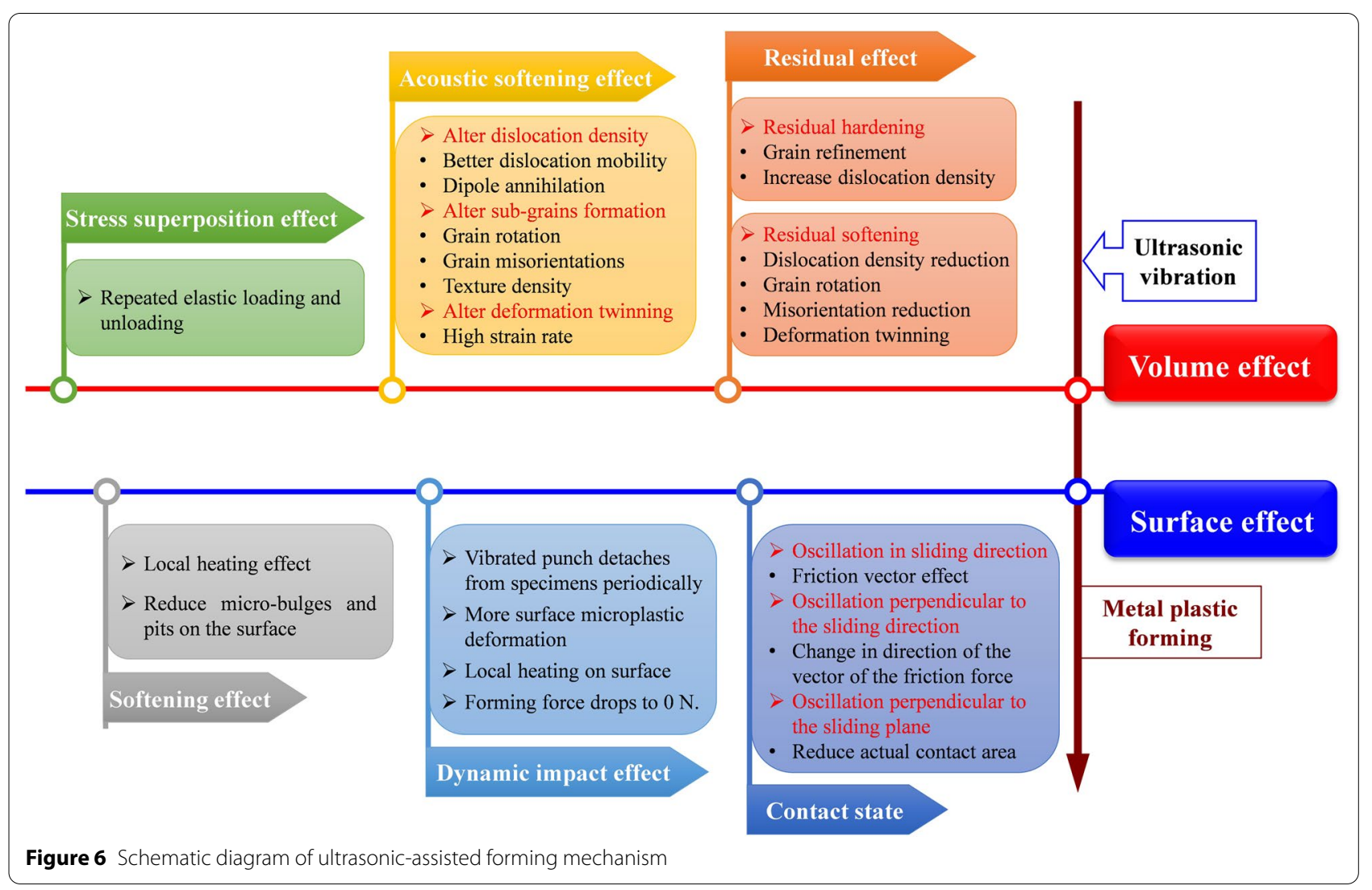


However, the experimental evidence and theoretical basis of the above assumptions are still unconvincing. There are noticeable differences in the reported effects of UV on the forming process for different sample sizes, UV application methods, and deformation states; the reasons for these differences have not yet been ascertained. There is still a lack of direct experimental verification for theories such as dipole annihilation and grain rotation. Moreover, there are coupling effects of multiple mechanisms such as the stress superposition effect, acoustic softening effect, and surface effect in the ultrasonic-assisted forming process. However, current studies have not realized a decoupling analysis of these mechanisms.

\section{Theoretical Models of Ultrasonic-Assisted Forming}

According to different ultrasonic mechanisms, research on theoretical models can be divided into two categories: (a) constitutive models for the volume effect, including phenomenological models and physically based models, and (b) theoretical models for the surface effect.

\subsection{Models of Volume Effect}

\subsubsection{Phenomenological Models}

To describe the phenomenon of acoustic softening and residual hardening, the mathematical model shown in Eq. (1) was constructed by introducing new parameters that reflect the ultrasonic defect intensity based on the synthetic theory of plastic deformation [56-58].

$$
H^{2}=\psi+\frac{2}{3} \sigma_{S}^{2}+F(|\vec{s}|, U) \psi_{u}, \psi=r \varphi,
$$

where $\psi$ is the defect intensity induced during plastic straining under (quasi) static loading, and $\psi_{u}$ is the defect intensity induced by UV. Function $F$ governs the manifestation of ultrasonic hardening or softening.

A constitutive model of 6063 aluminum alloy under ultrasonic-assisted upsetting at $298 \mathrm{~K}$ was constructed, as shown in Eq. (2), based on the Johnson-Cook model and the experimental results [59]:

$$
\Sigma=\left(C_{1}+C_{2} \varepsilon^{n}\right)\left[1+\left(C_{3} \ln \frac{\dot{\varepsilon}}{\dot{\varepsilon}_{r}}\right)\right]
$$

where $C_{3}$ is a constant. The stress-strain relationship under different ultrasonic conditions is reflected by varying the values of $C_{1}, C_{2}$, and $n$. For convenience, $C_{10}, C_{20}$, and $n_{0}$ represent the JC model parameters of conventional upsetting, while $C_{1 V}, C_{2 V}$, and $n_{0}$ represent those of ultrasonic-assisted upsetting, respectively.

Based on the varying trends of $C_{10} / C_{1 V}, C_{2 V} C_{20}$, and $n_{V} / n_{0}$ with the amplitudes and frequencies, the following relationships can be proposed:

$$
\left\{\begin{array}{l}
C_{10} / C_{1 V}=\alpha_{1} A^{2} f^{2}+\alpha_{2} A+\alpha_{3} f^{2}+\alpha_{4}, \\
C_{2 V} / C_{20}=\beta_{1} A+\beta_{2} f+\beta_{3}, \\
n_{V} / n_{0}=\eta_{1} A+\eta_{2} f+\eta_{3},
\end{array}\right.
$$

where $A$ and $f$ are the amplitude and frequency, respectively. This modified model reflects a decrease in the yield stress and an increase in the hardening index. However, the accuracy of the prediction results deteriorates under excessively high strain rates. To solve this problem, a cubic term of strain $\varepsilon$ is added to improve the prediction accuracy of the Johnson-Cook model, as shown in Eq. (4) $[60$

$$
\sigma=\left[A+B_{3} \varepsilon+B_{4} \varepsilon^{2}+B_{5} \varepsilon^{3}\right]\left(1+C_{2} \ln \dot{\varepsilon}^{*}\right) .
$$

\subsubsection{Models Based on Physical Mechanism}

A model for acoustic plasticity was developed to show the effects of UV on metal plasticity based on the crystal plasticity theory $[61,62]$. Acoustic softening is described through the thermal activation theory [63, 64]. Substituting $k T \ln \left(\dot{\gamma}_{0} / \dot{\gamma}_{p}\right) / \Delta F$ with $W$, the non-dimensional stress ratio $\lambda$ of the critical resolved shear stress $\tau$ to the mechanical threshold $\widehat{\tau}$ in the active slip system is given as

$$
\lambda=\frac{\tau}{\hat{\tau}}=1-W .
$$

In this model, the acoustic softening effect is mainly attributed to changes in the frequency factor $\dot{\gamma}_{0}$ and/or the activation energy $\Delta F$. Therefore, the stress ratio during UV can be expressed as

$$
\lambda_{V}=1-W_{V}=1-\left(W_{0}+\Delta W_{V}\right),
$$

where subscript $v$ indicates a variable under vibration, and subscript 0 indicates a variable without vibration or other forms of excitation energy. $W_{V}$ consists of the value without vibration $\left(W_{0}\right)$ and the net change due to vibration $\left(\Delta W_{V}\right)$. The changes in $\dot{\gamma}_{0}$ and/or $\Delta F$ are reflected in $\Delta W_{V}$. Therefore, the change in the non-dimensional stress ratio induced by the acoustic softening effect is modeled using Eq. (7):

$$
\Delta \lambda=\lambda_{V}-\lambda_{0}=-\Delta W_{v}=-\beta\left(E_{u} / \hat{\tau}\right)^{m},
$$

where $E_{u}$ is the acoustic energy density, and $\beta$ and $m$ are parameters to be determined experimentally.

Based on the dislocation evolution theory [65], the residual hardening effect was attributed to a change in the dislocation density. A logistic function was used to correct the dislocation storage coefficient, $k_{1}$. The revised dislocation density evolution model is shown in Eq. (8): 


$$
\frac{\mathrm{d} \rho}{\mathrm{d} \gamma}=k_{1}\left(1+\frac{K}{1+\left(K / P_{0}-1\right) e^{\Phi \zeta V}}\right) \sqrt{\rho}-k_{2} \rho .
$$

A similar work was carried out by Li et al. [9]. An exponential function was used to correct the dislocation storage coefficient, $k_{1}$ :

$$
k_{1}=k_{10} \xi_{2} A^{\eta},
$$

where $k_{10}$ is the pre-determined value based on the material properties, and $\xi_{2}$ and $\eta$ are determined based on the experiment. As a result, a modified acoustic softening model reflecting the change in both the thermal activation and dislocation evolution processes is expressed as

$$
\left\{\begin{array}{l}
\sigma=M G \alpha b \sqrt{\rho}\left\{\left[1-k T \ln \left(\frac{\dot{\nu}_{0}}{\dot{\gamma}_{p}}\right) / 0.5 G b^{3}\right]-\beta\left(\frac{E_{u}}{G \alpha b \sqrt{\rho}}\right)^{m}\right\}, \\
\frac{\mathrm{d} \rho}{\mathrm{d} \gamma}=k_{10} \xi_{2} A^{\eta} \sqrt{\rho}-\left(k_{20}\left(\frac{\dot{\varepsilon}}{\dot{\varepsilon}_{0}}\right)^{-1 / n}\right) \rho .
\end{array}\right.
$$

Deshpande et al. [36] considered that the mechanism of the acoustic softening effect is that the strain rate factor $\dot{\varepsilon}_{0}$ and the dynamic recovery term $k_{2}$ increase owing to the addition of acoustic energy during deformation. Thus, the dislocation density (and thus microstructure) evolution changes accordingly. The modified equation for $\dot{\varepsilon}_{0}$ is as follows:

$$
\dot{\varepsilon}_{0}=\dot{\varepsilon}_{00} \exp \left(\frac{-Q_{d} \chi}{k T E_{u}}\right),
$$

where $\dot{\varepsilon}_{00}$ is a constant, and $\chi$ is a constant with unit of $\mathrm{J} /$ $\mathrm{m}^{3}$.

Prabhakar et al. [66] proposed a constitutive model based on the dislocation density. The K-M model was used as the basic model framework, and parameters $\alpha$ and $n$ were modified to reflect the influence of UV.

$$
\begin{aligned}
& \alpha=\alpha_{0} \beta_{1}\left\{\dot{\varepsilon}^{\beta_{2}} T^{\beta_{3}}+\frac{\beta_{4}}{\beta_{1}} A^{2 \beta_{5}}\right\}, \\
& n=\beta_{6}\left\{T^{\beta_{7}}+\frac{\beta_{8}}{\beta_{6}} A^{2 \beta_{9}}\right\},
\end{aligned}
$$

where $\alpha_{0}$ is the athermal coefficient, and $\beta_{1-9}$ are material constants that account for the strain rate, temperature, and UV. The acoustic softening effect is accommodated through the constants $\beta_{4}$ and $\beta_{5}$, and the residual hardening effect can be incorporated by treating the material constant $\beta_{6}$ depending on the history of the induced ultrasonic pulses during plastic deformation.

In the study by Sedaghat et al. [67], the additive acoustic work of UV is defined as the amount of acoustic stress $\sigma_{\text {acoustic }}$ on the effective activation volume:

$$
\Delta F=\Delta G-\sigma_{\text {acoustic }} V .
$$

Considering the energy loss during ultrasonic transmission to overcome the barrier energy, an efficiency factor $(\eta)$ is introduced as follows:

$$
\sigma_{e f f, \text { acoustic }}=\eta \omega A \sqrt{\rho E},
$$

where $\omega$ is the ultrasonic frequency, $E$ is the elastic modulus, and $c$ is the sound velocity of the sample. The exact effective activation volume $(\mathrm{V})$ can be approximated using a compensation factor, $\lambda$ :

$$
V=\lambda \sqrt{3} k T\left(\frac{\partial \ln \dot{\varepsilon}}{\partial \sigma}\right) .
$$

Considering the drag stress at a very high strain, the overall flow stress can then be expressed as

$$
\begin{aligned}
\sigma= & \sigma_{G}+\hat{\sigma}_{t h}\left\{1-\left[-c_{2}\left(T \ln \left(\dot{\varepsilon} / \dot{\varepsilon}_{0}\right)+\frac{\xi_{3} V \omega A \sqrt{\rho E}}{k}\right)\right]^{1 / q}\right\}^{1 / p} \\
& +a \dot{\varepsilon}^{b} .
\end{aligned}
$$

Wang et al. [68] considered the influence of the stress superposition effect, and the stress reduction caused by the stress superposition effect was calculated according to the amplitude.

$$
\Delta \sigma_{s u}=-K\left(\alpha_{t} A\right)^{n},
$$

where $\alpha_{t}$ is the transmission coefficient, $A$ is the amplitude, $n$ is the hardening exponent, and $K$ is the material strength coefficient.

Consequently, the total reduction in the yield stress considering both the acoustic softening $\left(\Delta \sigma_{s 0}\right)$ and stress superposition $\left(\Delta \sigma_{s u}\right)$ is expressed as

$$
\Delta \sigma_{s}=\Delta \sigma_{s 0}+\Delta \sigma_{s u} .
$$

Furthermore, $\mathrm{Hu}$ et al. [55] considered the elastic deformation of the experimental equipment, and the force reduction $\Delta F$ caused by the stress superposition effect was obtained as

$$
\Delta F=A K
$$

The hybrid stiffness $K$ is derived as

$$
K=\frac{K_{a} \cdot K_{s}}{K_{a}+K_{s}} .
$$

$K_{a}$ and $K_{s}$ are the stiffness values of the experimental equipment and specimen, respectively. Considering the modification coefficient $\xi_{1}$ for the friction and transmission loss of acoustic energy, the true stress reduction $\Delta \sigma_{s u}$ is derived as follows: 


$$
\Delta \sigma_{s u}=\xi_{1} \frac{\Delta F\left(1-\frac{D_{a}}{H_{0}}\right)}{\pi r_{0}^{2} H_{0}} .
$$

Meng et al. [30] considered that the acoustic stress can be calculated by subtracting the stress reduction value caused by UV from the stress value calculated using the $\mathrm{K}-\mathrm{M}$ model. The stress reduction caused by the stress superposition effect is derived as

$$
\Delta \sigma_{s u}=R_{1} \frac{E A}{L_{0}},
$$

where $L_{0}$ is the length of the specimen's reduced section, and $R_{1}$ is a coefficient that reflects the influence of vibration damping. Furthermore, the stress reduction induced by acoustic softening has an exponential relationship with the acoustic energy density.

$$
\Delta \sigma_{s 0}=R_{2} E_{u}^{C},
$$

where $R_{2}$ is a coefficient affected by the energy absorption and loss, and the exponent $C$ is an experimental parameter ranging from 0.5 to 1 .

According to the coupled effect of UV and the grain size, the stress softening induced by UV has a saturation value [69]. Therefore, the modified acoustic softening term can be written as

$$
\Delta \sigma_{s 0}=\frac{R_{2}}{1+\beta_{1} \exp \left(-\beta_{2} E_{u}\right)} .
$$

The parameter $R_{2}$ reflects the saturated reduction value caused by acoustic softening, and is negatively related to grain size $D$ :

$$
R_{2}=a+b D^{-1},
$$

In terms of the crystal plasticity finite-element model, Siddiq and Sayed [31, 70] reported a modified evolution law for the plastic slip in system $i$. The modified model considering the acoustic softening effect is given by

$$
\dot{\gamma}^{i}=\gamma_{0}^{i} \operatorname{sgn}\left(\tau^{i}\right)\left\{\left|\frac{\tau^{i}}{g^{i} U_{s o f t}}\right|\right\}^{m},
$$

where $U_{\text {soft }}$ is the ultrasonic softening term exponentially related to the acoustic energy density [71]:

$$
U_{s o f t}=\left(1-d_{u t} E_{u}\right)^{e_{u t}},
$$

where $d_{u t}$ and $e_{u t}$ are acoustic softening parameters found from experiments.

\subsubsection{Comparison of Different Models}

The phenomenological model only describes the stressstrain relationship of the material through mathematical methods without considering the physical mechanism. This is convenient for the simulation calculations of an actual forming process. However, the parameters in this model have no actual physical meaning. In contrast, the crystal plasticity finite-element model reflects the influence of UV on microstructure evolution, but the calculation speed of the model is slow. For the internal variable model, the microscopic evolution mechanism and macroscopic mechanical response of the material were considered simultaneously. Therefore, both the physical authenticity and speed of the model were achieved.

Based on the crystal plasticity theory, including the thermal activation model and dislocation dynamics model, ultrasonic parameters, such as the amplitude, frequency, and acoustic energy density, were induced to reflect the volume effect (Figure 7). In the model established by Yao et al. [62], the acoustic softening phenomenon was described by modifying the thermal activation theory, and the residual hardening phenomenon was reflected by modifying the dislocation evolution model. The combined acoustic plasticity model accurately captured the acoustic softening and hardening in aluminum. The predicted stress-strain response of the vibrationassisted upsetting agreed well with the experimental results. To reflect the influence of the dislocation density on the acoustic softening effect, $\mathrm{Li}$ and Deshpande et al. $[9,36]$ modified $k_{1}$ and $k_{2}$, which are respectively the coefficients of the dislocation storage term that causes thermal hardening and the dislocation annihilation term accounting for the dynamic recovery. The relationship between the mechanical threshold $\widehat{\tau}$ and dislocation density $\rho$ was established based on the K-M model. Good agreement was found between the predictions and experimental results through the reasonable selection of parameters in the model. In addition, Prabhakar et al. [66] modified the parameters $\alpha$ and $n$ in their established dislocation density-based model. The acoustic softening effect and residual effect during the tensile tests can be accurately described by varying the parameters $\beta_{(1-9)}$.

There is significant dissipation and attenuation of acoustic energy in the actual forming process. Therefore, an effective coefficient $\xi_{3}=\eta \lambda$ reflecting the acoustic energy transfer efficiency was introduced in the acoustic softening model [67]. The accurate prediction of the forming force of the aluminum in the ultrasonicassisted upsetting, pressing, and incremental forming is realized by varying the effective coefficient. Moreover, some researchers considered employing the stress superposition effect to further improve the accuracy of the model $[30,55,68,69]$. The stress reduction caused 


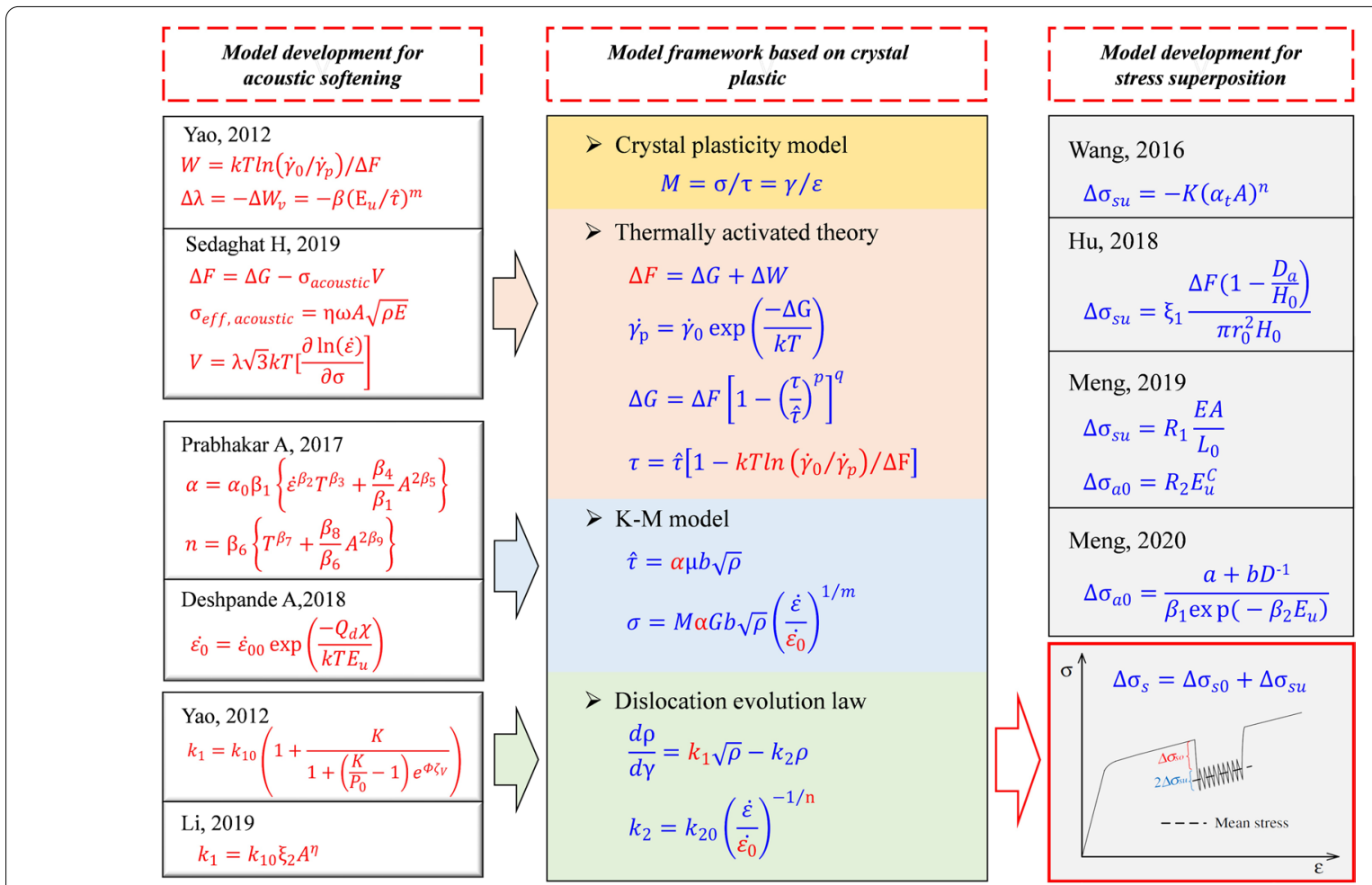

Figure 7 Ultrasonic-assisted forming models considering volume effect based on crystal plasticity theory

by the stress superposition effect is regarded as a variable related to the amplitude and elastic modulus.

\subsection{Models of Surface Effect}

There are three basic ways in which touching bodies vibrate against each other: (1) in-plane vibration in the sliding direction, (2) in-plane vibration perpendicular to the sliding direction, and (3) out-of-plane vibration perpendicular to the contact surface. To describe friction reduction, Storck et al. [41, 72] proposed an analytical model based on the Coulomb friction model. When the direction of the UV is perpendicular to the sliding direction, the average friction force $\bar{F}_{R, x}$ can be expressed as:

$$
\bar{F}_{R, x}(\zeta)=-\mu F_{N} \frac{2}{\pi \sqrt{1+\frac{1}{\zeta^{2}}}} K\left(\frac{1}{1+\zeta^{2}}\right) \operatorname{sgn}(\zeta), \zeta=\frac{\nu^{*}}{\hat{v}},
$$

where $\zeta$ is the ratio of the macroscopic velocity $v^{*}$ to the velocity amplitude of the harmonic component $\widehat{v}$. The reduction in the friction coefficient $\mu_{\text {perpendicular }}$ is defined by Eq. (30) as follows:

$$
\mu_{\text {perpendicular }}(\zeta)=\frac{\bar{F}_{R, x}(\zeta)}{-\mu F_{N}}
$$

When the direction of the UV is in-plane in the sliding direction, the average friction coefficient can be expressed as:

$$
\mu_{\text {parallel }}= \begin{cases}1, & \zeta \geq 1, \\ \frac{2}{\pi} \sin ^{-1}(\zeta), & -1<\zeta<1, \\ -1, & \zeta \leq-1 .\end{cases}
$$

Kumar et al. [40] established a theoretical prediction model for the friction in two vibration directions (Figure 8a). They found that the reduction in friction caused by the in-plane vibration in the sliding direction was greater than that caused by the in-plane vibration perpendicular to the sliding direction. Similar work was also done by Popv et al. [73, 74]. As shown in Figure 8b, the friction prediction models for three directions of ultrasonic application were established.

However, the above models are all based on the Coulomb friction model. In these models, the deformation in the contact zone was not considered, which led to a low prediction accuracy. To this end, dynamic Dahl's and Dupont's friction models $[75,76]$ that consider the elastoplastic characteristics of the contact surfaces were used. Dynamic friction prediction models were established when the in-plane vibration direction was parallel and perpendicular to the sliding direction [77, 78]. 


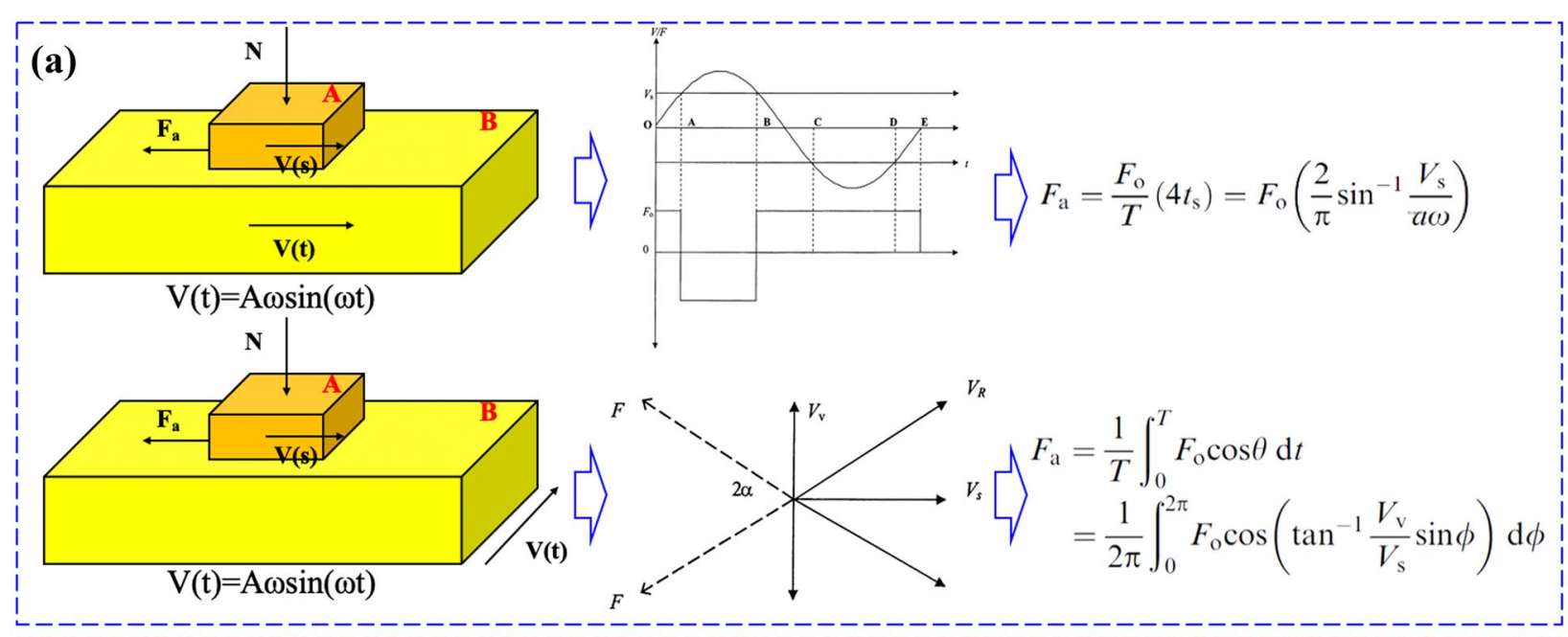

(b)
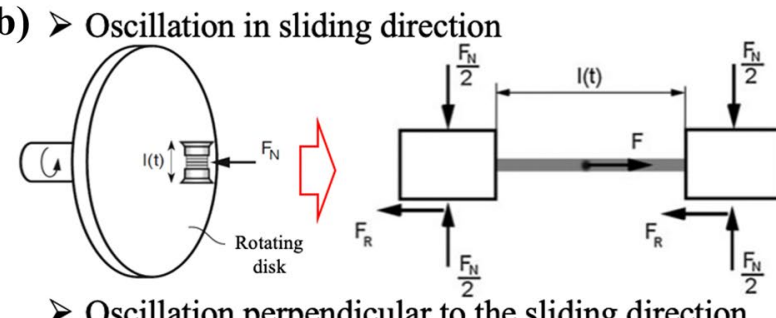

$$
\begin{aligned}
\frac{\mu}{\mu_{0}} & =\frac{1}{F_{N}}\left(\frac{F_{N}}{2} \frac{v_{\text {rel }, 1}}{\left|v_{\text {rel }, 1 \mid}\right|}+\frac{F_{N}}{2} \frac{v_{\text {rel }, 2}}{\mid v_{\text {rel }, 2 \mid}}\right) \\
& =\frac{1}{2 \pi} \int_{0}^{2 \pi} \frac{\langle v\rangle \cos \theta-\hat{v} \cos \xi}{\sqrt{\langle v\rangle^{2}+\hat{v}^{2} \cos ^{2} \xi-2\langle v\rangle \hat{v} \cos \theta \cos \xi}} d \xi
\end{aligned}
$$

Oscillation perpendicular to the sliding direction
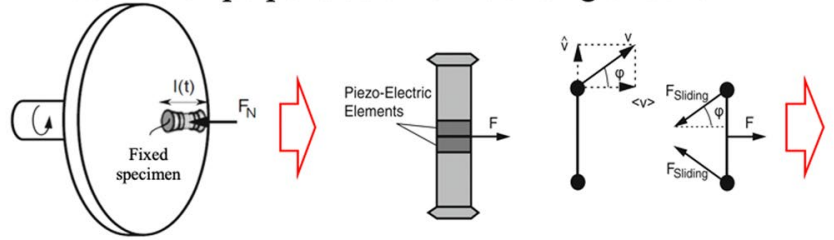

$$
\left\langle F_{R}\right\rangle=\frac{\mu_{0} F_{N}}{2 \pi} \int_{0}^{2 \pi} \frac{\mathrm{d} \xi}{\sqrt{1+\left(\frac{\hat{v}}{\langle v\rangle} \cos \xi\right)^{2}}}
$$

$>$ Oscillation perpendicular to the sliding plane
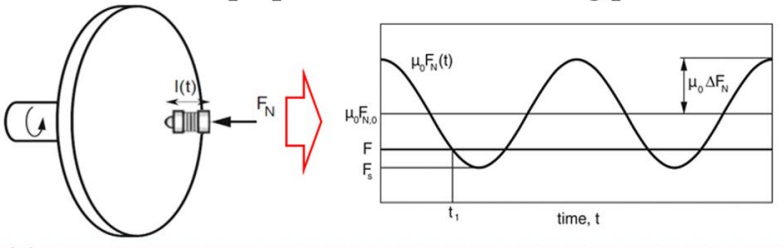

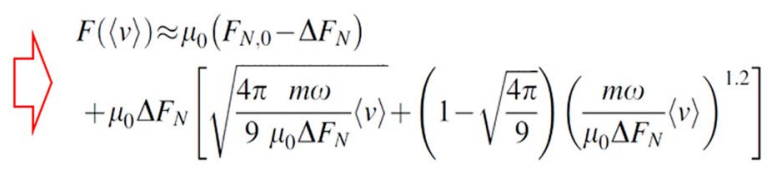

Figure 8 Friction models under different UV directions based on the classic Coulomb friction model: a Kumar models, b Popv models [40, 73, 74]

As shown in Figure 9, the maximum friction force $F_{F}$ is related to the elastic strain $z$, and the elastic strain rate $\dot{z}$ is related to the relative sliding velocity $v_{r}$ in the friction models of Dahl and Dupont. The prediction accuracy of the model is significantly improved compared with that of the classic Coulomb friction model. Moreover, Jadav et al. [79] combined these models and developed an analytical friction model for sliding bodies with coupled longitudinal and transverse vibrations.

When the UV direction was perpendicular to the contact surface, the plastic deformation of the contact surfaces changed the actual contact area. The friction model for a metal sheet was established based on the elastoplastic contact mechanics of rough surfaces [45]. The total actual contact area $A_{r}$, which is the summation of the elastic and plastic areas, can be computed as follows:

$$
\begin{aligned}
& A_{r}=A_{e}+A_{p} \\
& A_{e}=\frac{c \pi \beta A_{n}}{\lambda^{2}}\left[1-\left(1+\lambda \frac{\omega_{c}}{R_{q}}\right) e^{-\lambda \omega_{c} / R_{q}}\right] e^{-\lambda d / R_{q}},
\end{aligned}
$$




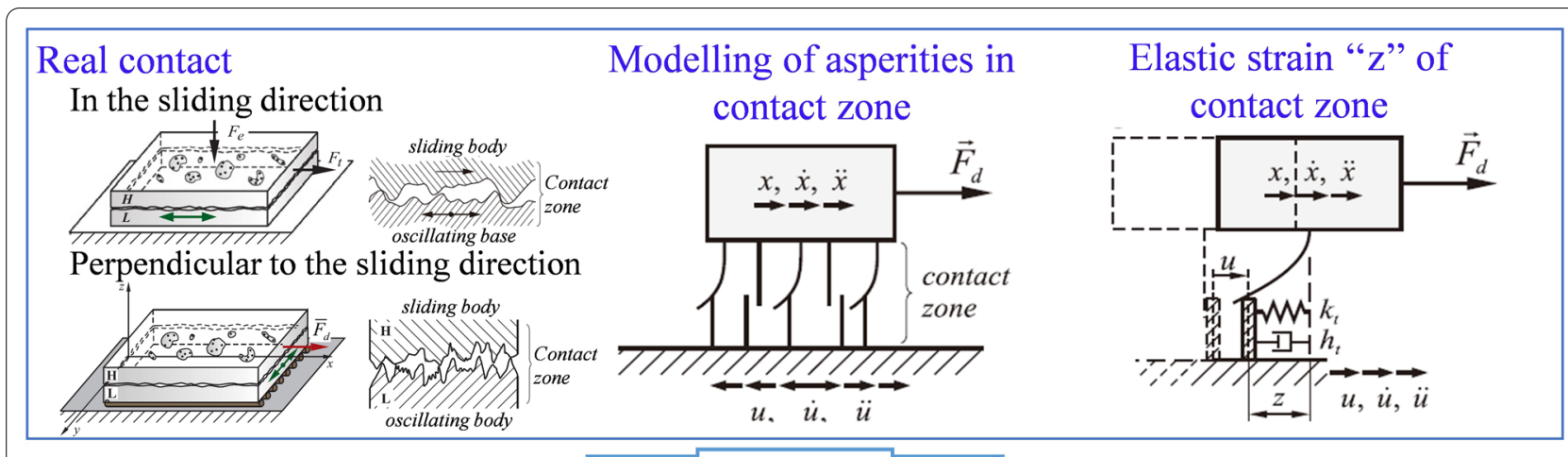

The magnitude of friction force

$$
F_{F}=k_{t} z \quad m \ddot{x}=k_{d}\left(v_{d} t-x\right)-k_{t} z
$$

Dahl model

$\dot{z}=\frac{d z}{d t}=v_{r}\left[1-\frac{k_{t}}{\mu F_{N}} \operatorname{sgn}\left(v_{r}\right) z\right]^{a}$

$>$ The velocity of forced vibrations
Dupont model

$\dot{z}=\frac{d z}{d t}=v_{r}\left[1-\beta\left(z, v_{r}\right) \frac{k_{t}}{\mu F_{N}} \operatorname{sgn}\left(v_{r}\right) z\right]^{a}$

$$
\dot{u}=u_{0} \omega \cos (\omega t)
$$

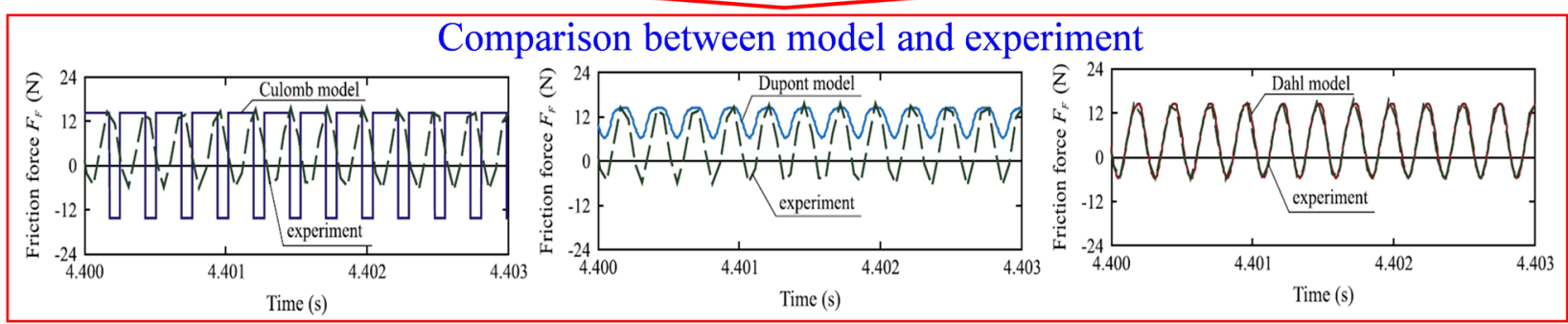

Figure 9 Friction model based on Dahl's and Dupont's friction models [77, 78]

$$
A_{p}=\frac{c \pi \beta A_{n}}{\lambda^{2}}\left(2+\lambda \frac{\omega_{c}}{R_{q}}\right) e^{-\lambda\left(d+\omega_{c}\right) / R_{q}} .
$$

Therefore, the dynamic friction after applying UV is acquired by

$$
F_{t}^{\prime}=\frac{2}{T} \int_{0}^{T / 2} K_{t}^{\prime} \delta \mathrm{d} t=\frac{2}{T} \int_{0}^{T / 2} \frac{A_{r}^{\prime 2} E^{*}(\delta+u)}{(d+v)^{3}} \mathrm{~d} t .
$$

\subsection{Discussion}

With the constant iteration and refinement of researchers, theoretical models of acoustic plasticity have become increasingly reliable. The volume and surface effects during uniaxial tension, compression, and friction tests can be accurately predicted by introducing ultrasonic parameters such as amplitude, acoustic energy density, and effective coefficient into typical models. This is beneficial when analyzing the material deformation characteristics in the ultrasonic-assisted forming process, and provides a basis for understanding the underlying mechanisms of UV.

However, there are still some problems when applying the modified model to the actual forming process. During the actual ultrasonic-assisted forming process, the material is constrained by multiple molds, and the vibration mode is not constant. Material forming is a dynamic process, and the dissipation rate of the acoustic energy changes dynamically. Thus, it is not appropriate to characterize the dissipation effect 
using a constant. In addition, the natural frequency of the material changes with the accumulation of plastic deformation, thereby reducing the prediction accuracy of the model. Therefore, a theoretical model that predicts the effect of UV should be established by comprehensively considering the influence of various factors.

\section{Discussion of Advantages in Processing Performance}

As shown in Figure 10, for different forming processes, there are different advantages of UV with respect to the processing performance, and they mainly including the following points: (a) reducing the forming force during deformation, (b) improving the surface quality of the workpiece, (c) improving the forming limit and preventing forming defects, and (d) strengthening the surface structure and improving the material fatigue life and corrosion resistance.

\subsection{Reduce the Forming Force}

The forming force can be significantly reduced by applying UV to the mold or blank during deformation. During the incremental forming of aluminum, the vertical and horizontal forces were reduced by $23.5 \%$ and $26.3 \%$, respectively $[80,88]$. During the extrusion process of 1015 carbon steel, the forming force was reduced from $70 \mathrm{kN}$ to $30 \mathrm{kN}$ by applying axial UV to the tool [89]. A similar phenomenon also occurs in forming processes such as upsetting [90], deep drawing

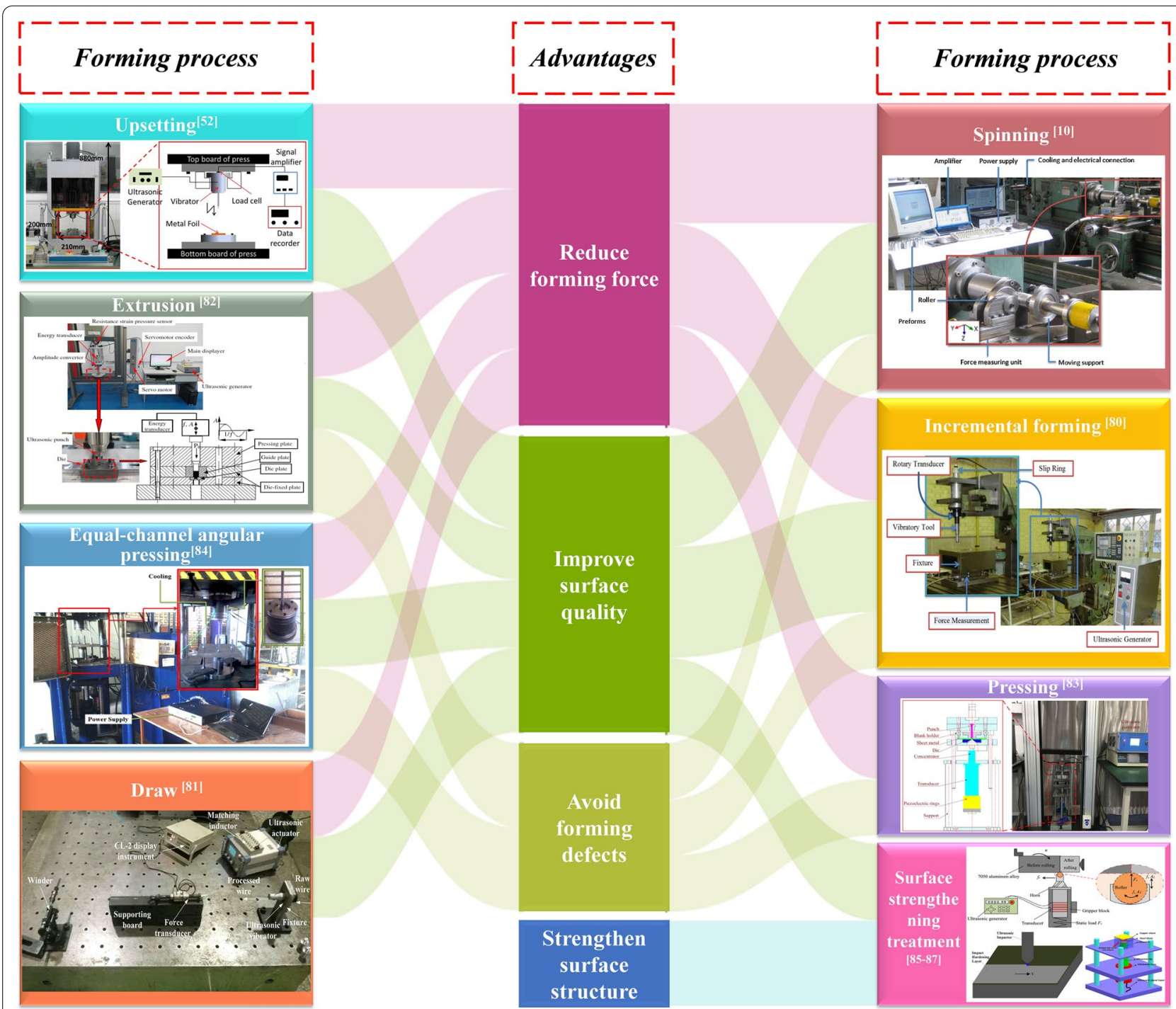

Figure 10 Advantages in processing performance [10, 52, 80-87] 
$[13,91]$, and equal-channel angular pressing (ECAP) [92].

The UV application method significantly impacts the reduction in the forming force. During the wire drawing process, the radial UV applied to the die reduced the drawing force more effectively than the axial UV $[42,93]$. The load reduction caused by the longitudinal and torsional composite UV was more obvious compared with the above two application methods (Figure 11a) [81]. However, in the process of ECAP, the force reduction was more obvious when the vertical UV was directly applied to the blank compared with the application of the axial UV to the punch and the horizontal UV to the blank (Figure 11b) [94, 95]. Moreover, the magnitude of the force reduction can be improved by increasing the ultrasonic power, frequency, and amplitude within a certain range $[96,97]$.

There are two possible reasons for the reduction in forming force. First, the lubrication condition between the blank and the mold is improved after applying UV owing to the surface effect, while the friction coefficient and forming force are reduced accordingly [42, 89, 96,
98]. Second, the UV can significantly reduce the flow stress during deformation owing to the volume effect, and a greater ultrasonic power results in a more significant reduction in the flow stress [67, 89, 94]. Moreover, the force reduction and temperature increase caused by UV are noticeable for materials with high yield strength [3].

\subsection{Improve the Surface Quality}

Surface quality directly affects the performance of the workpiece. As shown in Figure 12, the application of UV significantly reduced the surface roughness in processes such as upsetting [52], drawing [81, 96], incremental forming $[80,88,99]$, extrusion $[82,89,100]$ and spinning [10]. In addition, there were noticeable differences in the improvement effects produced by different UV application methods. In the wire drawing process of titanium, the furrows became narrow and fragments and transverse cracks decreased after applying the longitudinal UV to the die. However, the fragments and transverse cracks nearly vanished, but the furrows became much longer

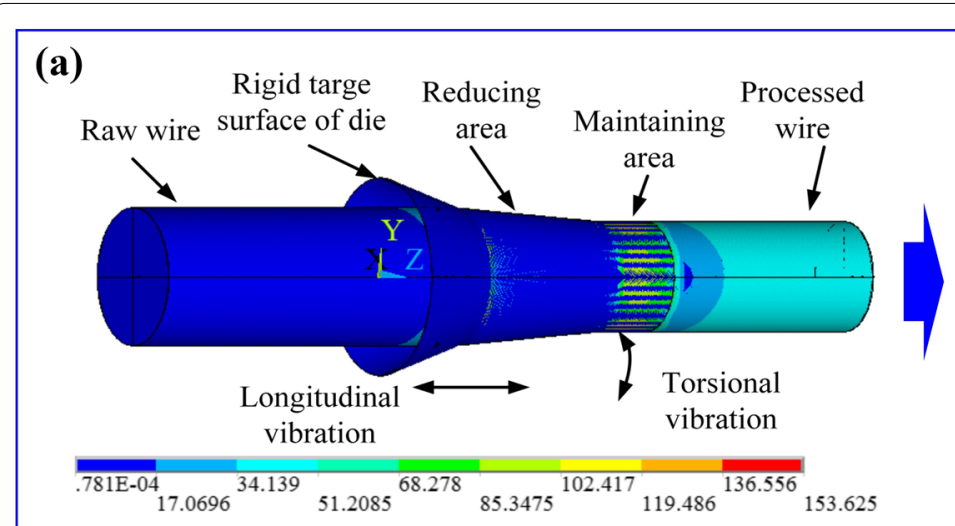

Finite element model and the stress contour plot.

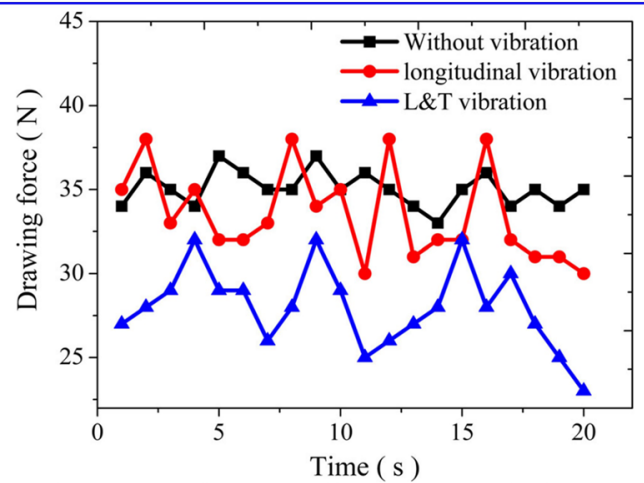

Variation of drawing forces with different superimposed vibration.

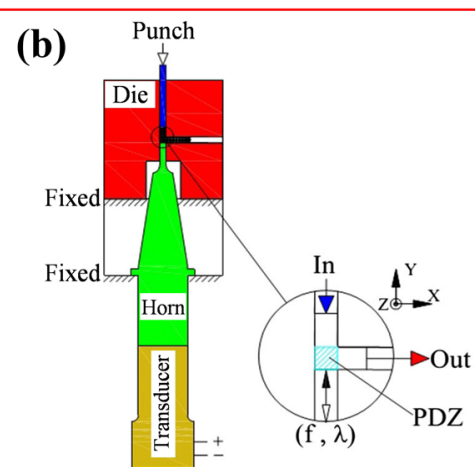

Vertical ultrasonic vibration (V)

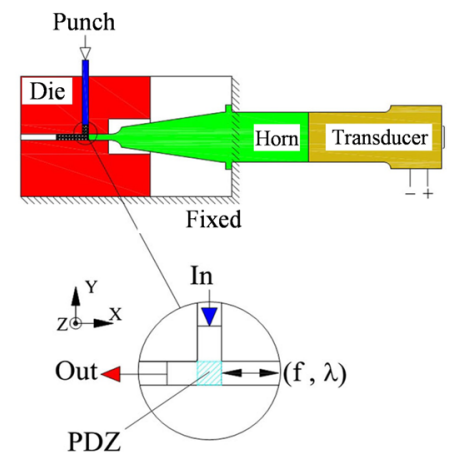

Lateral ultrasonic vibration (L)

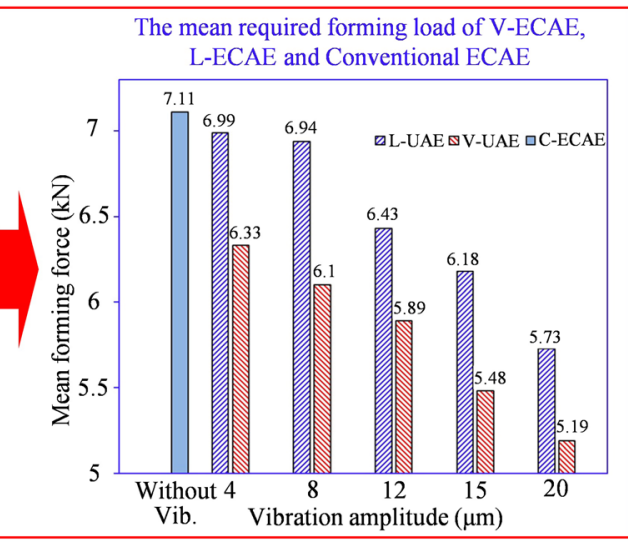

Figure 11 The influence of UV on forming force: a wire drawing [81]; b ECAP [94] 


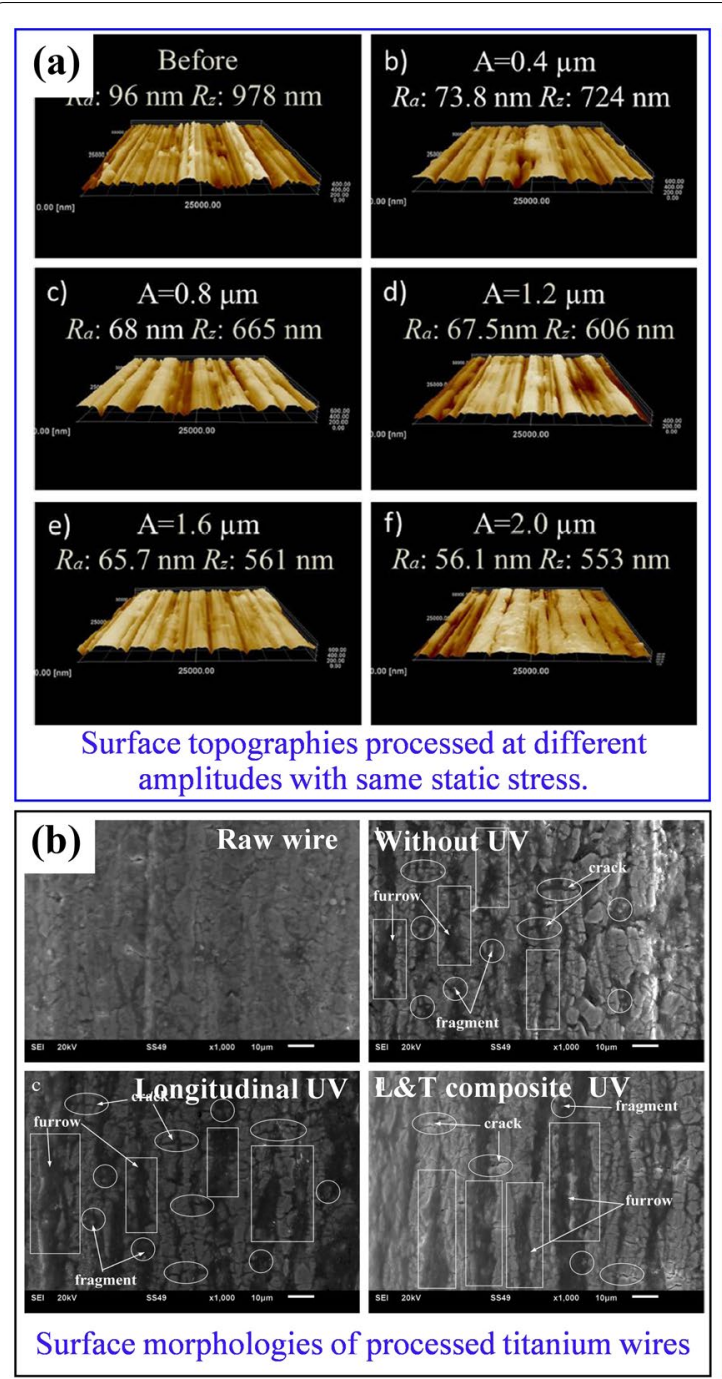

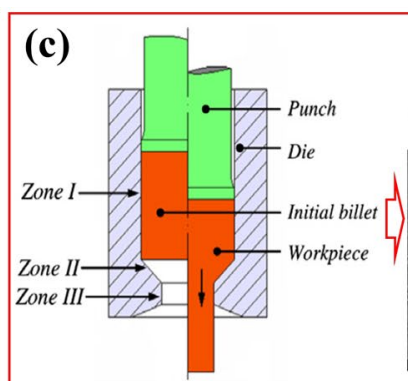

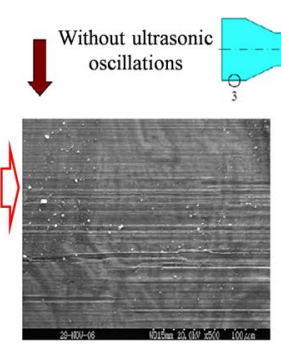

With ultrasonic oscillations

Ultrasonic forward-rod extrusion process schematic
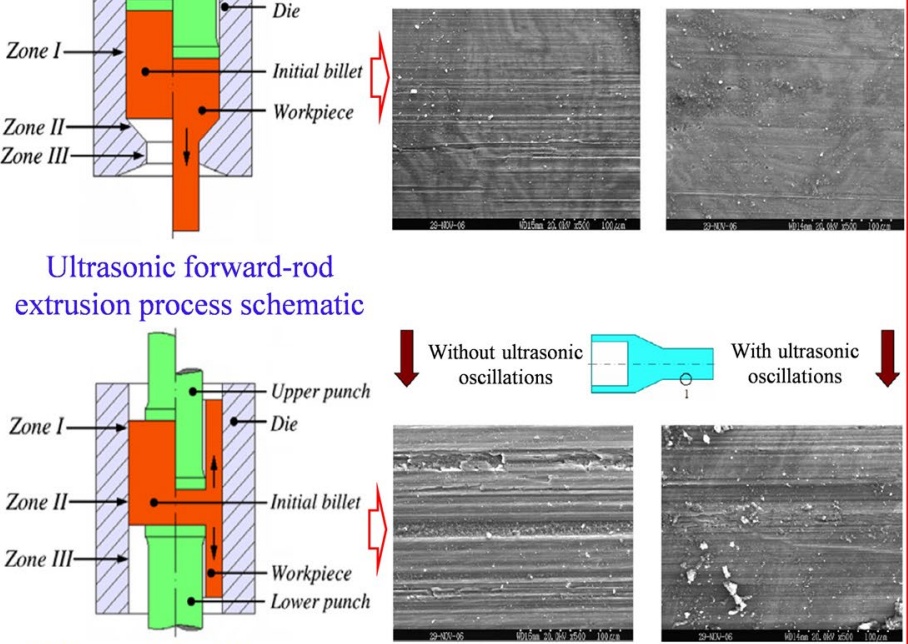

Ultrasonic double cup backward extrusion process schematic

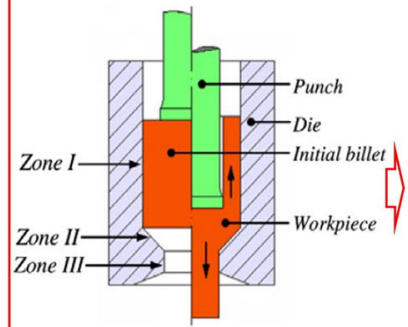

Ultrasonic forward rod backward extrusion process schematic

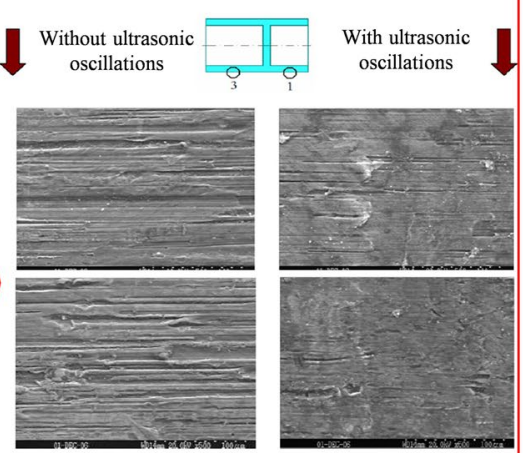

Comparison between the surfaces obtained with and without ultrasonic oscillations

Figure 12 Effect of UV on surface quality: a upsetting [52], b wire drawing [81], c extrusion [100]

and larger after applying the longitudinal and torsional composite UV (Figure 12b) [81].

The effect of UV on the surface quality of the blank can be explained as follows. First, the movement direction of the mold changes periodically under the action of UV. Thus, the static friction force is converted into sliding friction, and the material flow on the blank surface is improved. Second, the mold impacts the surface of the blank at a high frequency, thereby softening the surface asperities of the blank. The material flows from the bump to the pit under the action of the mold, thereby improving the surface topography. Moreover, UV increases the temperature between the mold/blank contact surfaces, thereby increasing the effectiveness of the lubricant $[10$, $52,81,101]$.

Generally, the surface quality improves as the amplitude increases [52, 97]. However, under an excessively high amplitude, the high-frequency impact of the mold excessively increases the temperature between the mold/ blank contact surfaces and reduces the lubricant effectiveness. Moreover, there is adhesive friction between the mold and blank at high temperatures, which causes damage to the blank surface and deteriorates the surface quality $[10,81]$.

\subsection{Avoid Forming Defects}

Forming defects such as wrinkles and cracks are prone to appear during the forming process owing to the uneven deformation distribution. After applying UV, the acoustic energy is absorbed by the internal defects of the blank, thereby reducing the deformation resistance and improving the material flow [27, 67, 101]. In addition, high-frequency vibrations produce local high temperatures at the mold/blank contact surfaces. As a 
result, the residual stress is reduced and the forming accuracy is improved [3].

The prevention of forming defects through UV has been applied in many forming processes (Figure 13). In the process of deep drawing, the application of high-frequency vibration to the blank holder and die increased the drawing height and reduced the wrinkles of the blank [83, 91]. In the incremental forming process, the application of UV to the tool reduces the springback coefficient and improves the dimensional accuracy of the workpiece $[80,88,101]$. In the copper micro-extrusion process, the application of UV promoted plastic deformation and grain refinement [82]. In the process of ECAP, UV increases the efficiency of grain refinement and eliminates folding defects [95]. In addition, the yield strength and tensile strength of the formed workpiece increased accordingly [84, 102]. In addition, the above-mentioned effects become more noticeable with an increase in the ultrasonic power and amplitude.

\subsection{Strengthen Surface Structure}

To improve the performance of the workpiece, the surface plastic forming method was used for surface modification in the final stage of processing. In recent years, researchers have developed various surface treatment (UST) processes based on UV, such as ultrasonic shot peening [103-105], ultrasonic impact treatment [106108], and ultrasonic surface rolling [85, 109, 110]; the principles of the different UST processes are similar. Severe plastic deformation on the material surface is caused by high-frequency vibration tools, which rapidly change the structure of the surface layer and improve the mechanical properties of the material, such as the elongation and yield ratio $[86,87,108,111-115]$.

Owing to the uneven deformation distribution along the thickness direction, the UST can obtain a gradient structure composed of a thermal-mechanical coupled layer, an elongated nanograin layer, an elongated ultrafine grain layer, refined grain, and a low-strain matrix layer from the surface to the inside. In addition, the microhardness presents a gradient distribution, as shown in Figure 14a [110]. A high-density base texture is formed on the material surface after UST [107, 116], and the grain size was refined to within $100 \mathrm{~nm}$. Moreover, the refined grain layer thickness, surface hardness, and hardening rate will increase as the treatment time and amplitude increase [86, 105, 117].

Dislocation slip is the main mechanism for nanograin formation, while twinning provides a synergistic effect under conditions of high strain rate and high deformation. The grains sub-divided into sub-grain boundaries are transformed into nano-lath structures by the dislocation slip, and the direction of the
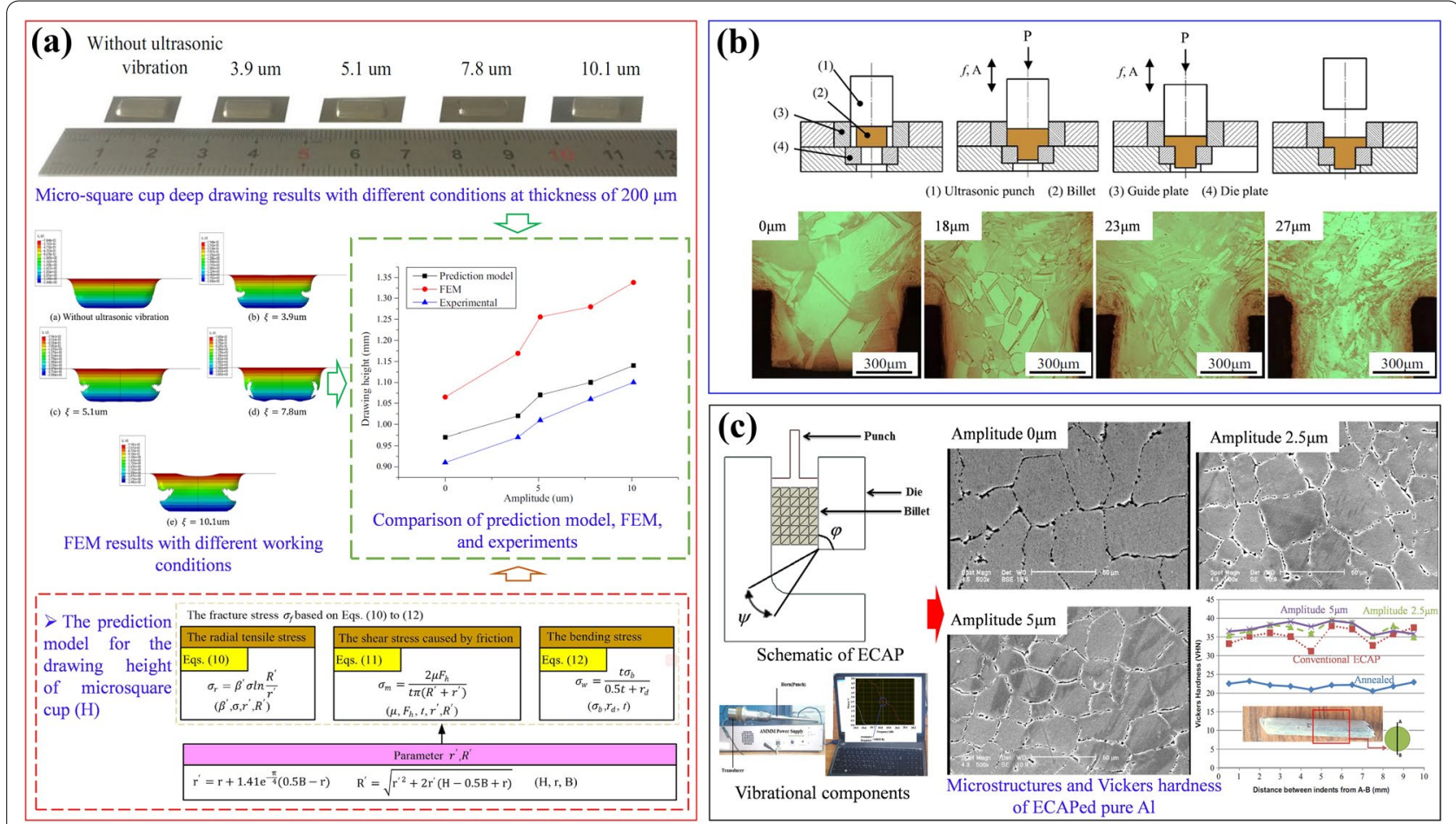

Figure 13 Effect of UV on forming defects: a drawing [93], b extrusion [82], c ECAP [95] 

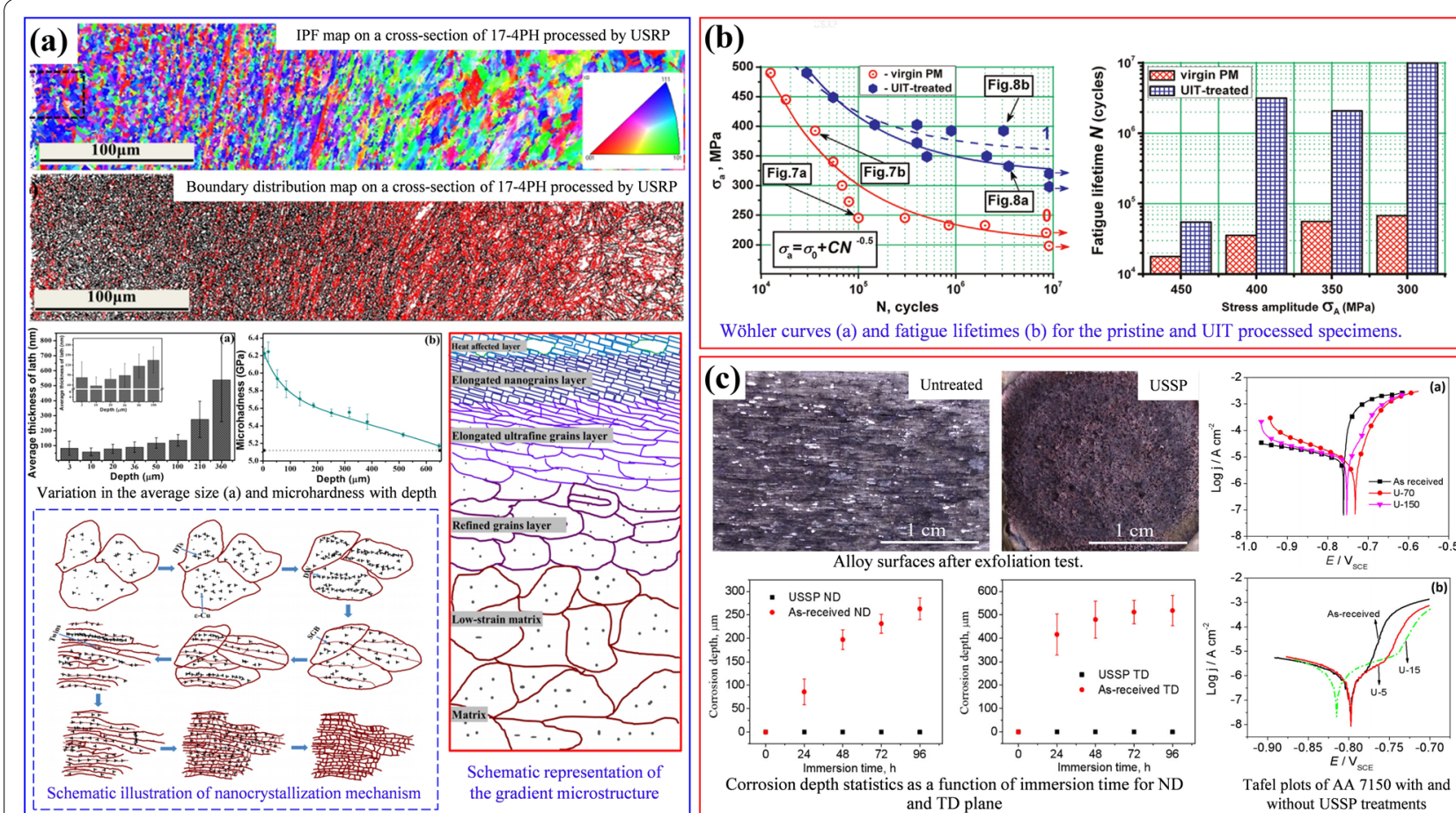

Wöhler curves (a) and fatigue lifetimes (b) for the pristine and UIT processed specimens.
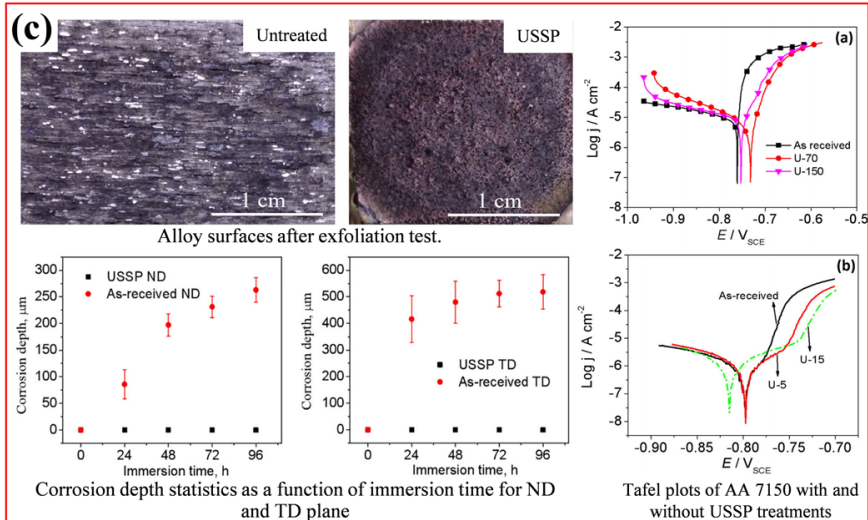

Figure 14 Strengthen surface structure via UST: a surface gradient microstructure [110], b improvement of fatigue resistance [106], c improvement of the corrosion resistance [129]

nano-lath is dominated by the slip direction. Twinning affects the refinement of nano-lath microstructures owing to the interaction between twinning and dislocation, resulting in the formation of equiaxed nanograins. In addition, the precipitation phase also plays a positive role in grain refinement [110].

The UST generates a residual compressive stress on the workpiece surface, thereby improving the damage tolerance and fatigue life of the material [103, 104, 118123]. For the Ti-6Al-4V alloy, the fatigue strength was increased by $60 \%-72.7 \%$ and the fatigue lifetime was extended by two orders of magnitude using UST (Figure 14b) [106, 109, 124]. Moreover, the fretting fatigue lifetime of $300 \mathrm{M}$ steel increased by a factor of 4.7 times that of UST [125]. Generally, the gradient distributions of grain size, residual stress, and microhardness can be considered as the reasons for improving the fretting fatigue lifetime, and the residual compressive stress plays the most critical role [126].

Furthermore, UST can improve the corrosion resistance of materials $[125,127,128]$. The exfoliation corrosion sensitivity of AA7150 alloy decreased after UST. In addition, the micro-scale intergranular corrosion was inhibited, and the pitting potential shifted in the positive direction for both the normal and transverse planes (Figure 14c) [129]. This enhancement in corrosion resistance is attributed to the formation of equiaxed nanograins on the material surface.

\section{Conclusion and Outlook}

In this paper, a systematic and detailed review of studies on ultrasonic-assisted forming is presented. First, the basic principle of ultrasonic-assisted forming was introduced. Second, the macro and micro mechanisms of UV on deformation were discussed from the perspective of the volume effect and surface effect. Then, different theoretical models were compared. Finally, the advantages of UV in terms of the processing performance were discussed. It is shown that UV promotes material flow during deformation and has huge advantages in terms of improving the forming performance. However, there are still challenges in the widespread application of ultrasonic-assisted forming. Owing to restrictions such as the modification cost and equipment stability, most ultrasonic-assisted forming technologies are still in the laboratory stage. In addition, even though there are many existing studies, there is no systematic and clear explanation of the UV mechanism. Moreover, the prediction accuracy of related models also needs to be improved. Based on the above challenges, the detailed outlooks in the ultrasonic-assisted 
forming are identified by incorporating them with the analysis of Figure 15.

(1) Develop high-efficiency, stable, intelligent, and high-power ultrasonic equipment.

Compared with the continuous in-depth studies in ultrasonic-assisted forming, practical applications in factories are still rare. This situation may be caused by the complicated ultrasonic equipment structure and the high cost. Moreover, the inherent resonant frequency of the blank changes with dynamic deformation, resulting in the instability of the UV. To improve the performance of the ultrasonic equipment and reduce the cost, in future, it is necessary to develop an ultrasonic transducer with a higher output power, as well as an ultrasonic generator with online feedback and intelligent adjustment functions of amplitude and frequency.

(2) Application of ultrasonic-assisted forming to difficult-to-form components.

In this study, the geometric structure of the component formed by the ultrasonic-assisted forming process was relatively simple. For difficult-to-form components made of superalloys such as titanium, defects such as wrinkling and cracking are prone to

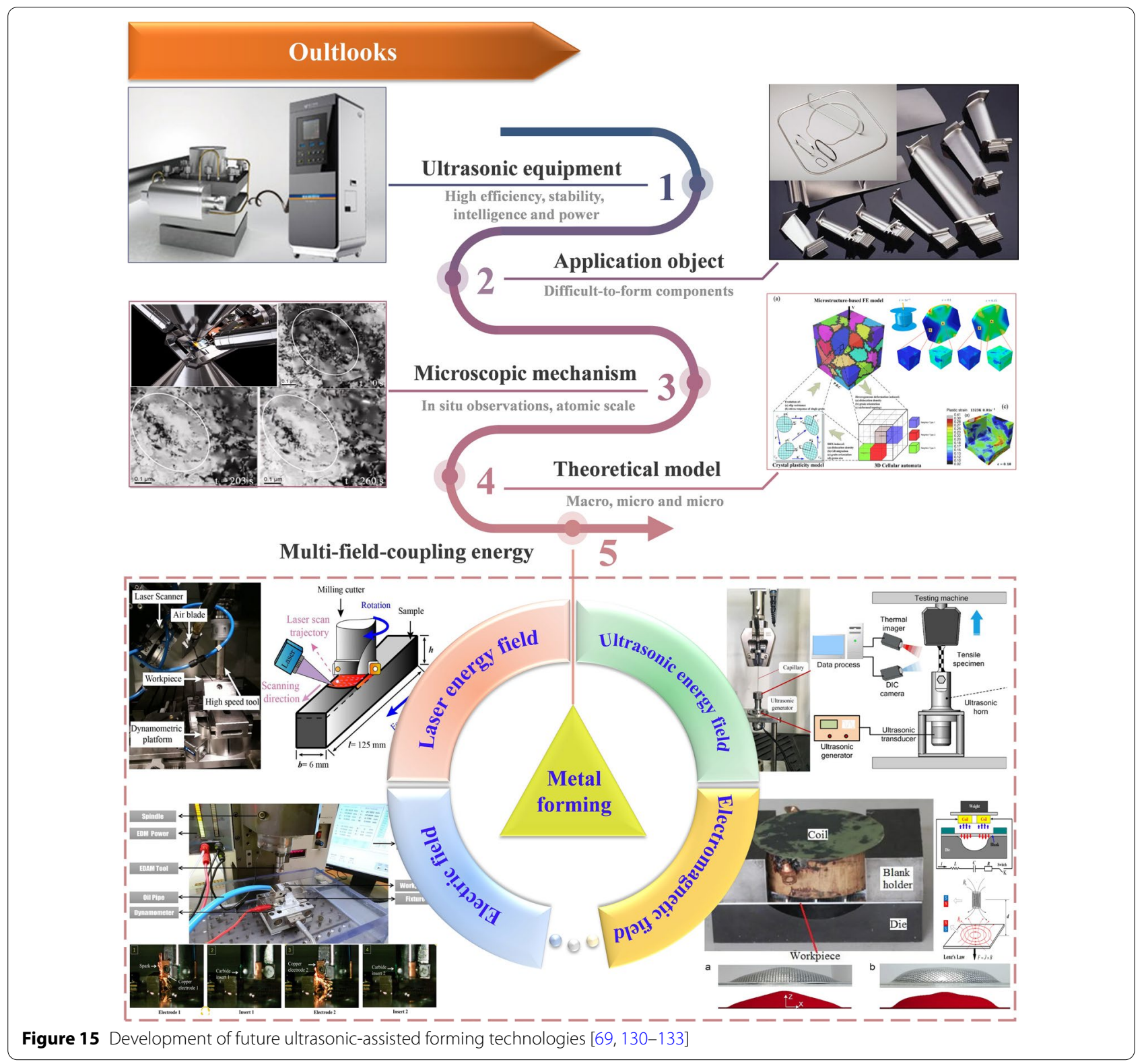


occur during deformation owing to the high yield strength, high hardening rate, and complex geometric structures. Therefore, it is important to study the deformation laws and improve the forming quality of difficult-to-form components by applying UV.

Furthermore, the deformation conditions of difficultto-form components are complicated. The stress and strain states in different regions of the component are different, and the effects of UV are different. Therefore, it is necessary to study the reasonable control of the uneven deformation and strengthening of difficult-to-form components in the ultrasonic-assisted forming process.

(3) Understand the mechanism of UV.

Existing explanations of the ultrasonic mechanism could reveal the behavior of ultrasonic-assisted forming under certain conditions. However, these explanations are unconvincing because of the lack of reliable experimental verification and theoretical analyses. Therefore, scientific experiments should be conducted to study the influence of the material structure, scale effect, UV application method, and stress state on the ultrasonic-assisted forming process in the future. Thus, a more essential explanation of the ultrasonic mechanism should be provided on a microscopic scale.

Recently, in situ, quasi-in-situ electron backscattered diffraction technology and in situ transmission electron microscope (TEM) technology have been increasingly used in the study of microscopic evolution mechanisms. Therefore, the real-time observation of the influence of UV on the evolution of dislocations and grains is critical to further verify these theories, such as dislocation dipole annihilation and grain rotation. In addition, it is important to realize a decoupling analysis of complex mechanisms such as stress superposition, the acoustic softening effect, and the ultrasonic dynamic impact in the ultrasonic-assisted forming process.

(4) Establish systematic and accurate theoretical models.

A systematic and accurate theoretical model can help to guide the design of ultrasonic-assisted forming processes. However, existing models do not fully consider the coupling between multiple ultrasonic mechanisms. This review argues that the theoretical model of the ultrasonic-assisted forming process should be developed from the following two perspectives.

First, based on a deep understanding of the ultrasonic mechanism, a microstructure prediction model should be established via crystal plasticity, molecular dynamics, and other methods. Therefore, the effect of UV on the atom vibration, dislocation slip, and grain rotation will be predicted accurately, and the relationship between the microstructural evolution and the macroscopic mechanical properties will be established. However, the stress state and the acoustic energy transmission efficiency constantly change during the ultrasonic-assisted forming process. Therefore, it is necessary to accurately describe the transmission efficiency of acoustic energy and to comprehensively examine the impact of multiple ultrasonic mechanisms on the deformation.

(5) Multi-field coupling to improve the forming quality. Compared with a single acoustic energy field, the application of multiple energy fields, for example, acoustic fields, magnetic fields, electropulsing, and lasers in the forming process can significantly improve the forming quality. For example, by performing electropulsing-assisted ultrasonic surface rolling, the surface quality of the workpiece is significantly improved, while the surface cracks and defects are reduced [134]. Moreover, a nano/ submicroscale oxide structure can be achieved on Ti6Al4V through an ultrasonic shot peening-induction heating approach [135]. From the above examples, it is shown that multi-field-coupling assisted forming technologies will become a research hotspot in the future.

Acknowledgements

Not applicable.

\section{Authors' Contributions}

GS carried out studies in reviews of ultrasonic-assisted forming. He wrote the draft. $\mathrm{HL}$ assisted with the structure and language of the manuscript. MZ conducted proofreading and made some critical revisions. All authors read and approved the final manuscript.

\section{Authors' Information}

Guangda Shao, born in 1996, is currently a PhD candidate at Shaanxi Key Laboratory of Precision Forming Technology and Equipment, School of Materials Science and Engineering, Northwestern Polytechnical University, China. He received his bachelor's degree from Northwestern Polytechnical University, China, in 2017. His research interests include the theory and technology of precision plastic forming.

Hongwei Li, born in 1979, is currently a professor at Shaanxi Key Laboratory of Precision Forming Technology and Equipment, School of Materials Science and Engineering, Northwestern Polytechnical University, China. He received his PhD from Northwestern Polytechnical University, China, in 2007.

Mei Zhan, born in 1972, is currently a professor at Shaanxi Key Laboratory of Precision Forming Technology and Equipment, School of Materials Science and Engineering, Northwestern Polytechnical University, China. She received her PhD from Northwestern Polytechnical University, China, in 2001.

\section{Funding}

Supported by National Natural Science Foundation of China (Grant No. U1737212), National Science and Technology Major Project of China (Grant No. J2019-VII-0014-0154), and Shaanxi Provincial Natural Science Foundation for Distinguished Young Scholars of China (Grant No. 2019JC-09). 


\section{Competing Interests}

The authors declare no competing financial interests.

Received: 27 September 2020 Revised: 29 March 2021 Accepted: 2 September 2021

Published online: 30 October 2021

\section{References}

[1] S Kumar, C SWu, G K Padhy, et al. Application of ultrasonic vibrations in welding and metal processing: A status review. Journal of Manufacturing Processes, 2017, 26: 295-322.

[2] H Zhou, H Cui, Q H Qin. Influence of ultrasonic vibration on the plasticity of metals during compression process. Journal of Materials Processing Technology, 2018, 251: 146-159.

[3] Y Long, Y Li, J Sun, et al. Effects of process parameters on force reduction and temperature variation during ultrasonic assisted incremental sheet forming process. The International Journal of Advanced Manufacturing Technology, 2018, 97(1-4): 13-24.

[4] F Blaha, B Langenecker. Tensile deformation of zinc crystal under ultrasonic vibration. Science of Nature, 1955, 42(20).

[5] F Ning, W Cong. Ultrasonic vibration-assisted (UV-A) manufacturing processes: State of the art and future perspectives. Journal of Manufacturing Processes, 2020, 51: 174-190.

[6] Y Liu, L Hua. Review of study on high-intensity ultrasonic vibrations assisted plastic deformation process. Journal of Plasticity Engineering, 2015, 22(4): 8-14.

[7] A G Rozner. Effect of ultrasonic vibration on coefficient of friction during strip drawing. The Journal of the Acoustical Society of America, 1971, 49(5A): 1368-1371.

[8] M Urbakh, J Klafter, D Gourdon, et al. The nonlinear nature of friction. Nature, 2004, 430(6999): 525

[9] Y Li, Z Cheng, X Chen, et al. Constitutive modeling and deformation analysis for the ultrasonic-assisted incremental forming process. The International Journal of Advanced Manufacturing Technology, 2019, 104(5-8): 2287-2299.

[10] M A Rasoli, A Abdullah, M Farzin, et al. Influence of ultrasonic vibrations on tube spinning process. Journal of Materials Processing Technology, 2012, 212(6): 1443-1452.

[11] Y Bai, M Yang. Optimization of metal foils surface finishing using vibration-assisted micro-forging. Journal of Materials Processing Technology, 2014, 214(1): 21-28.

[12] G E Nevill, F R Brotzen. Effect of vibrations on the yield strength of a low carbon steel. Proceeding-American Society for Testing Material, ASTM, Philadelphia, 1957: 751-754

[13] B Langenecker. Effects of ultrasound on deformation characteristics of metals. IEEE Transactions on Sonics \& Ultrasonics, 1966, 13(1): 1-8.

[14] Z Huang, M Lucas, M J Adams. Influence of ultrasonics on upsetting of a model paste. Ultrasonics, 2002, 40(1): 43-48.

[15] Y Daud, M Lucas, Z Huang. Modelling the effects of superimposed ultrasonic vibrations on tension and compression tests of aluminium. Journal of Materials Processing Technology, 2007, 186(1-3): 179-190.

[16] X Zhuang, JWang, H Zheng, et al. Forming mechanism of ultrasonic vibration assisted compression. Transactions of Nonferrous Metals Society of China, 2015, 25(7): 2352-2360.

[17] Z Yao, G Kim, L Faidley, et al. Effects of superimposed high-frequency vibration on deformation of aluminum in micro/meso-scale upsetting. Journal of Materials Processing Technology, 2012, 212(3): 640-646.

[18] S Ali, S Hinduja, J Atkinson, et al. The effect of ultra-low frequency pulsations on tearing during deep drawing of cylindrical cups. International Journal of Machine Tools and Manufacture, 2008, 48(5): 558-564.

[19] R Pohlman, E Lehfeldt. Influence of ultrasonic vibration on metallic friction. Ultrasonics, 1966, 4(4): 178-185.

[20] T Liu, J Lin, Y Guan, et al. Effects of ultrasonic vibration on the compression of pure titanium. Ultrasonics, 2018, 89: 26-33.

[21] T Gao, X Liu, KYu, et al. Effects of ultrasonic vibration on tensile properties of TC1 titanium alloy sheet. Rare Metal Materials and Engineering, 2019, 48(1): 286-292.

[22] B Langenecker. Work-softening of metal crystals by alternating the rate of glide strain. Acta Metallurgica, 1961, 9(10): 937-940.
[23] H Huang, A Pequegnat, B H Chang, et al. Influence of superimposed ultrasound on deformability of Cu. Journal of Applied Physics, 2009, 106: 113514.

[24] J Kang, X Liu, M Xu. Plastic deformation of pure copper in ultrasonic assisted micro-tensile test. Materials Science and Engineering: A, 2020, 785: 139364

[25] V Fartashvand, A Abdullah, S A Sadough Vanini. Investigation of Ti-6Al-4V alloy acoustic softening. Ultrason Sonochem, 2017, 38: 744-749.

[26] Q Mao, N Coutris, H Rack, et al. Investigating ultrasound-induced acoustic softening in aluminum and its alloys. Ultrasonics, 2020, 102: 106005.

[27] J Hung, Y Tsai. Investigation of the effects of ultrasonic vibrationassisted micro-upsetting on brass. Materials Science and Engineering: $A$, 2013, 580: 125-132.

[28] Y Wang, Y Hou, Y Liu, et al. Investigation of ultrasonic deformation characteristics of ultrathin miniaturized TA1 foil. Materials Science and Engineering: A, 2020, 777: 139070.

[29] R K Dutta, R H Petrov, R Delhez, et al. The effect of tensile deformation by in situ ultrasonic treatment on the microstructure of low-carbon steel. Acta Materialia, 2013, 61(5): 1592-1602.

[30] B Meng, B N Cao, M Wan, et al. Constitutive behavior and microstructural evolution in ultrasonic vibration assisted deformation of ultrathin superalloy sheet. International Journal of Mechanical Sciences, 2019, 157-158: 609-618.

[31] A Siddiq, TEl Sayed. Acoustic softening in metals during ultrasonic assisted deformation via CP-FEM. Materials Letters, 2011, 65(2): 356-359.

[32] TKosugi, Y Kogure, Y Hiki, et al. Effect of pressure on dislocation damping in aluminum crystals. Tokyo Sugaku Kaisya Zasshi, 1986, 54(7): 2565-2575.

[33] KW Siu, A H W Ngan, I P Jones. New insight on acoustoplasticity Ultrasonic irradiation enhances subgrain formation during deformation. International Journal of Plasticity, 2011, 27(5): 788-800.

[34] S Jiang, TYang, H Sun, et al. Influence of ultrasonic vibration on tensile properties and dislocation distribution of titanium foil. Journal of Materials Engineering, 2019, 47(2): 84-89.

[35] K H Westmacott, B Langenecker. Dislocation structure in ultrasonically irradiated aluminum. Physical Review Letters, 1965, 14(7): 221-222.

[36] A Deshpande, $\mathrm{K} \mathrm{Hsu}$. Acoustic energy enabled dynamic recovery in aluminium and its effects on stress evolution and post-deformation microstructure. Materials Science and Engineering: A, 2018, 711:62-68.

[37] R K Dutta, R H Petrov, M J M Hermans, et al. Accommodation of plastic deformation by ultrasound-induced grain rotation. Metallurgical and Materials Transactions A, 2015, 46(8): 3414-3422.

[38] A Deshpande, A Tofangchi, K Hsu. Microstructure evolution of Al6061 and copper during ultrasonic energy assisted compression. Materials Characterization, 2019, 153:240-250.

[39] H Zhou, H Cui, Q Qin, et al. A comparative study of mechanical and microstructural characteristics of aluminium and titanium undergoing ultrasonic assisted compression testing. Materials Science and Engineering: A, 2017, 682: 376-388.

[40] V C Kumar, I M Hutchings. Reduction of the sliding friction of metals by the application of longitudinal or transverse ultrasonic vibration. Tribo/ogy International, 2004, 37(10): 833-840.

[41] W Lenkiewicz. The sliding friction process: effect of external vibrations. Wear, 1969, 13(2): 99-108.

[42] M Murakawa, M Jin. The utility of radially and ultrasonically vibrated dies in the wire drawing process. Journal of Materials Processing Technology, 2001, 113: 81-86.

[43] K Siegert, J Ulmer. Reduction of sliding friction by ultrasonic waves. Prog. Eng., 1998, 5(1): 25-28.

[44] D P Hess, A Soom. Normal vibrations and friction under harmonic loads: Part II-Rough planar contacts. Journal of Tribology, 1991, 113(1): 87-92.

[45] M Cao, J Li, Y Liu, et al. Frictional characteristics of sheet metals with superimposed ultrasonic vibrations. Journal of Central South University, 2018, 25(8): 1879-1887.

[46] H Sofuoglu, J Rasty. On the measurement of friction coefficient utilizing the ring compression test. Tribology International, 1999, 32(6): 327-335. 
[47] Z Xie, Y Guan, L Zhu, et al. Investigations on the surface effect of ultrasonic vibration-assisted 6063 aluminum alloy ring upsetting. The International Journal of Advanced Manufacturing Technology, 2018, 96(912): 4407-4421.

[48] J Lin, J Li, T Liu, et al. Evaluation of friction reduction and frictionless stress in ultrasonic vibration forming process. Journal of Materials Processing Technology, 2021, 288: 116881.

[49] R Shahrokh, A Ghaei, M Farzin, et al. Experimental and numerical investigation of ultrasonically assisted micro-ring compression test. The International Journal of Advanced Manufacturing Technology, 2017, 95(912): 3487-3495

[50] J C Hung, Y C Tsai, C Hung. Frictional effect of ultrasonic-vibration on upsetting. Ultrasonics, 2007, 46(3): 277-284

[51] Z H Yao, D Q Mei, Z C Chen. Modeling of metallic surface topography modification by high-frequency vibration. Journal of Sound and Vibration, 2016, 363: 258-271.

[52] Y Bai, M Yang. The influence of superimposed ultrasonic vibration on surface asperities deformation. Journal of Materials Processing Technology, 2016, 229: 367-374.

[53] J Hu, T Shimizu, TYoshino, et al. Ultrasonic dynamic impact effect on deformation of aluminum during micro-compression tests. Journal of Materials Processing Technology, 2018, 258: 144-154.

[54] W Presz. Influence of experimental setup parameters on ultrasonic assisted micro-upsetting. Arch. Metall. Mater., 2020, 65(1): 423-431.

[55] J Hu, T Shimizu, M Yang. Investigation on ultrasonic volume effects: Stress superposition, acoustic softening and dynamic impact. Ultrason Sonochem, 2018, 48: 240-248.

[56] R Andrew. Non-classical problems of irreversible deformation in terms of the synthetic theory. Acta Polytechnica Hungarica, 2010, 7(3): 25-62.

[57] A Rusinko. Analytical description of ultrasonic hardening and softening. Ultrasonics, 2011, 51(6): 709-714.

[58] A Rusinko, K Rusinko. Synthetic theory of irreversible deformation in the context of fundamental bases of plasticity. Mechanics of Materials, 2009, 41(2): 106-120.

[59] Z Xie, Y Guan, J Lin, et al. Constitutive model of 6063 aluminum alloy under the ultrasonic vibration upsetting based on Johnson-Cook model. Ultrasonics, 2019, 96: 1-9.

[60] J Lin, J Li, T Liu, et al. Investigation on ultrasonic vibration effects on plastic flow behavior of pure titanium: Constitutive modeling. Journal of Materials Research and Technology, 2020, 9(3): 4978-4993.

[61] G I Taylor. Plastic Strain in metals. Journal of the Institute of Metals, 1938 62: 307-324

[62] Z Yao, G Kim, Z Wang, et al. Acoustic softening and residual hardening in aluminum: Modeling and experiments. International Journal of Plasticity, 2012, 39: 75-87.

[63] U F Kocks. Constitutive behavior based on crystal plasticity. London: Elsevier Applied Science, 1987: 1-88.

[64] U Messerschmidt. Dislocation dynamics during plastic deformation. London: Springer, 2010.

[65] A S Krausz, K Krausz. Unified constitutive laws of plastic deformation. San Diego: Academic Press, 1996.

[66] A Prabhakar, G C Verma, H Krishnasamy, et al. Dislocation density based constitutive model for ultrasonic assisted deformation. Mechanics Research Communications, 2017, 85: 76-80.

[67] H Sedaghat, W Xu, L Zhang. Ultrasonic vibration-assisted metal forming: Constitutive modelling of acoustoplasticity and applications. Journal of Materials Processing Technology, 2019, 265: 122-129.

[68] C J Wang, Y Liu, B Guo, et al. Acoustic softening and stress superposition in ultrasonic vibration assisted uniaxial tension of copper foil: Experiments and modeling. Materials \& Design, 2016, 112: 246-253.

[69] B Meng, B N Cao, M Wan, et al. Ultrasonic-assisted microforming of superalloy capillary: Modeling and experimental investigation. Journal of Manufacturing Processes, 2020, 57: 589-599.

[70] A Siddiq, TE Sayed. A thermomechanical crystal plasticity constitutive model for ultrasonic consolidation. Computational Materials Science, 2012, 51(1): 241-251.

[71] A Siddiq, T El Sayed. Ultrasonic-assisted manufacturing processes: variational model and numerical simulations. Ultrasonics, 2012, 52(4): 521-529.

[72] H Storck, W Littmann, J Wallaschek, et al. The effect of friction reduction in presence of ultrasonic vibrations and its relevance to travelling wave ultrasonic motors. Ultrasonics, 2002, 40: 379-383.
[73] V L Popov, J Starcevic, A E Filippov. Influence of ultrasonic in-plane oscillations on static and sliding friction and intrinsic length scale of dry friction processes. Tribology Letters, 2010, 39(1): 25-30.

[74] E Teidelt, J Starcevic, V L Popov. Influence of ultrasonic oscillation on static and sliding friction. Tribology Letters, 2012, 48(1): 51-62.

[75] A Dupont. Elasto-plastic friction model: contact compliance and stiction. Proceedings of the American Control Conference, Chicago: IEEE, 2000: 1072-1077.

[76] P R Dahl. Solid friction damping of mechanical vibrations. AlAA Journal, 1976, 14(12): 1675-1682.

[77] P Gutowski, M Leus. The effect of longitudinal tangential vibrations on friction and driving forces in sliding motion. Tribology International, 2012, 55: 108-118.

[78] P Gutowski, M Leus. Computational model for friction force estimation in sliding motion at transverse tangential vibrations of elastic contact support. Tribology International, 2015, 90: 455-462.

[79] P Udaykant Jadav, R Amali, O B Adetoro. Analytical friction model for sliding bodies with coupled longitudinal and transverse vibration. Tribology International, 2018, 126: 240-248.

[80] S Amini, A Hosseinpour Gollo, H Paktinat. An investigation of conventional and ultrasonic-assisted incremental forming of annealed AA1050 sheet. The International Journal of Advanced Manufacturing Technology, 2016, 90(5-8): 1569-1578.

[81] CYang, X Shan, T Xie. Titanium wire drawing with longitudinal-torsional composite ultrasonic vibration. The International Journal of Advanced Manufacturing Technology, 2015, 83(1-4): 645-655.

[82] Y Lou, J S He, H Chen, et al. Effects of vibration amplitude and relative grain size on the rheological behavior of copper during ultrasonicassisted microextrusion. The International Journal of Advanced Manufacturing Technology, 2016, 89(5-8): 2421-2433.

[83] C Zha, W Chen. Theories and experiments on effects of acoustic energy field in micro-square cup drawing. The International Journal of Advanced Manufacturing Technology, 2019, 104(9-12): 4791-4802.

[84] F Ahmadi, M Farzin, M Meratian, et al. Improvement of ECAP process by imposing ultrasonic vibrations. The International Journal of Advanced Manufacturing Technology, 2015, 79(1-4): 503-512.

[85] H Liu, J Zheng, Y Guo, et al. Residual stresses in high-speed two-dimensional ultrasonic rolling 7050 aluminum alloy with thermal-mechanical coupling. International Journal of Mechanical Sciences, 2020, 186: 105824.

[86] F Yin, Y Liu, R Xu, et al. Nanograined surface fabricated on the pure copper by ultrasonic shot peening and an energy-density based criterion for peening intensity quantification. Journal of Manufacturing Processes, 2018, 32: 656-663.

[87] M Li, Q Zhang, B Han, et al. Investigation on microstructure and properties of AlxCoCrFeMnNi high entropy alloys by ultrasonic impact treatment. Journal of Alloys and Compounds, 2020, 816: 152626.

[88] M Vahdati, R Mahdavinejad, S Amini. Investigation of the ultrasonic vibration effect in incremental sheet metal forming process. Proceedings of the Institution of Mechanical Engineers Part B Journal of Engineering Manufacture, 2017, 231(6): 971-982.

[89] S A A A Mousavi, H Feizi, R Madoliat. Investigations on the effects of ultrasonic vibrations in the extrusion process. Journal of Materials Processing Technology, 2007, 187-188: 657-661.

[90] J C Hung, C Hung. The influence of ultrasonic-vibration on hot upsetting of aluminum alloy. Ultrasonics, 2005, 43(8): 692-698.

[91] T Jimma, Y Kasuga, N Iwaki, et al. An application of ultrasonic vibration to the deep drawing process. Journal of Materials Processing Technology, 1998, 80-81: 406-412.

[92] F Djavanroodi, H Ahmadian, K Koohkan, et al. Ultrasonic assisted-ECAP. Ultrasonics, 2013, 53(6): 1089-1096.

[93] M Hayashi, M Jin, SThipprakmas, et al. Simulation of ultrasonic-vibration drawing using the finite element method (FEM). Journal of Materials Processing Technology, 2003, 140(1-3): 30-35.

[94] S Bagherzadeh, K Abrinia, Y Liu, et al. The effect of combining highintensity ultrasonic vibration with ECAE process on the process parameters and mechanical properties and microstructure of aluminum 1050. The International Journal of Advanced Manufacturing Technology, 2017, 88(1-4): 229-240.

[95] SBagherzadeh, KAbrinia, Q Han. Analysis of plastic deformation behavior of ultrafine-grained aluminum processed by the newly developed 
ultrasonic vibration enhanced ECAP: Simulation and experiments. Journal of Manufacturing Processes, 2020, 50: 485-497.

[96] K Siegert, J Ulmer. Superimposing ultrasonic waves on the dies in tube and wire drawing. Journal of Engineering Materials \& Technology, 2001, 123(4): 517-523.

[97] P Li, J He, Q Liu, et al. Evaluation of forming forces in ultrasonic incremental sheet metal forming. Aerospace Science and Technology, 2017, 63: 132-139.

[98] Y Ashida, H Aoyama. Press forming using ultrasonic vibration. Journal of Materials Processing Technology, 2007, 187-188: 118-122.

[99] R Cheng, N Wiley, M Short, et al. Applying ultrasonic vibration during single-point and two-point incremental sheet forming. Procedia Manufacturing, 2019, 34: 186-192.

[100] C Bunget, G Ngaile. Influence of ultrasonic vibration on micro-extrusion. Ultrasonics, 2011, 51(5): 606-616

[101] Y Li, W Zhai, Z Wang, et al. Investigation on the material flow and deformation behavior during ultrasonic-assisted incremental forming of straight grooves. Journal of Materials Research and Technology, 2020, 9(1): 433-454

[102] Y Liu, S Suslov, Q Han, et al. Microstructure of the pure copper produced by upsetting with ultrasonic vibration. Materials Letters, 2012, 67(1): 52-55.

[103] R K Agrawal, V Pandey, A BarhanpurkarNaik, et al. Effect of ultrasonic shot peening duration on microstructure, corrosion behavior and cell response of $\mathrm{cp}$-Ti. Ultrasonics, 2020, 104: 106110.

[104] S A Martinez, S Sathish, M P Blodgett, et al. Effects of fretting fatigue on the residual stress of shot peened Ti-6Al-4V samples. Materials Science and Engineering: A, 2005, 399(1): 58-63.

[105] F Yin, M Rakita, S Hu, et al. In-situ method to produce nanograined metallic powders/flakes via ultrasonic shot peening. Journal of Manufacturing Processes, 2017, 26: 393-398.

[106] A I Dekhtyar, B N Mordyuk, D G Savvakin, et al. Enhanced fatigue behavior of powder metallurgy Ti-6Al-4V alloy by applying ultrasonic impact treatment. Materials Science and Engineering: A, 2015, 641: 348-359

[107] A V Panin, M S Kazachenok, A I Kozelskaya, et al. The effect of ultrasonic impact treatment on the deformation behavior of commercially pure titanium under uniaxial tension. Materials \& Design, 2017, 117: $371-381$

[108] C Zhou, F Jiang, D Xu, et al. A calculation model to predict the impact stress field and depth of plastic deformation zone of additive manufactured parts in the process of ultrasonic impact treatment. Journal of Materials Processing Technology, 2020, 280: 116599.

[109] C Liu, D Liu, X Zhang, et al. Fretting fatigue characteristics of Ti-6Al-4V alloy with a gradient nanostructured surface layer induced by ultrasonic surface rolling process. International Journal of Fatigue, 2019, 125: 249-260

[110] D Liu, D Liu, X Zhang, et al. Surface nanocrystallization of 17-4 precipitation-hardening stainless steel subjected to ultrasonic surface rolling process. Materials Science and Engineering: A, 2018, 726: 69-81.

[111] XWu, N Tao, Y Hong, et al. Microstructure and evolution of mechanically-induced ultrafine grain in surface layer of AL-alloy subjected to USSP. Acta Materialia, 2002, 50(8): 2075-2084.

[112] WY Tsai, J C Huang, Y J Gao, et al. Relationship between microstructure and properties for ultrasonic surface mechanical attrition treatment. Scripta Materialia, 2015, 103: 45-48.

[113] S Efim Sh, K Oleg V, V Vladimir N. Physics and mechanism of ultrasonic impact. Ultrasonics, 2006, 44: 533-538.

[114] M A Vasylyev, B N Mordyuk, S I Sidorenko, et al. Influence of microstructural features and deformation-induced martensite on hardening of stainless steel by cryogenic ultrasonic impact treatment. Surface and Coatings Technology, 2018, 343: 57-68.

[115] X Yang, X Wang, X Ling, et al. Enhanced mechanical behaviors of gradient nano-grained austenite stainless steel by means of ultrasonic impact treatment. Results in Physics, 2017, 7: 1412-1421.

[116] R Hairullin, A Kozelskaya, M Kazachenok. Effect of ultrasonic impact treatment on microstructure and mechanical properties of commercial purity titanium. Key Engineering Materials, 2016, 685: 330-333.
[117] L Zhu, Y Guan, Yanjie Wang, et al. Influence of process parameters of ultrasonic shot peening on surface nanocrystallization and hardness of pure titanium. The International Journal of Advanced Manufacturing Technology, 2017, 89: 1451-1468.

[118] G M Bagheri S Review of shot peening processes to obtain nanocrystalline surfaces in metal alloys. Surface Engineering, 2013, 25(1): 3-14.

[119] HW Huang, Z B Wang, J Lu, et al. Fatique behaviors of AISI 316L stainless steel with a gradient nanostructured surface layer. Acta Materialia, 2015, 87: 150-160.

[120] V Pandey, K Chattopadhyay, N C Santhi Srinivas, et al. Low Cycle Fatigue behavior of AA7075 with surface gradient structure produced by Ultrasonic Shot Peening. Procedia Structural Integrity, 2016, 2: 3288-3295

[121] G R Jinu, P Sathiya, G Ravichandran, et al. Investigation of the fatigue behaviour of butt-welded joints treated by ultrasonic peening process and compared with fatigue life assessment standards. The International Journal of Advanced Manufacturing Technology, 2009, 40(1-2): 74-83.

[122] B N Mordyuk, G I Prokopenko, M A Vasylyev, et al. Effect of structure evolution induced by ultrasonic peening on the corrosion behavior of AISI-321 stainless steel. Materials Science and Engineering: A, 2007 , 458(1): 253-261.

[123] XXu, D Liu, X Zhang, et al. Influence of ultrasonic rolling on surface integrity and corrosion fatigue behavior of 7B50-T7751 aluminum alloy. International Journal of Fatigue, 2019, 125: 237-248.

[124] C S Liu, D X Liu, X H Zhang, et al. Effect of the ultrasonic surface rolling process on the fretting fatigue behavior of Ti-6Al-4V alloy. Materials, 2017, 10: 833-844.

[125] W Zhao, D Liu, X Zhang, et al. Improving the fretting and corrosion fatigue performance of $300 \mathrm{~m}$ ultra-high strength steel using the ultrasonic surface rolling process. International Journal of Fatigue, 2019, 121: 30-38.

[126] D Liu, D Liu, X Zhang, et al. An investigation of fretting fatigue behavior and mechanism in 17-4PH stainless steel with gradient structure produced by an ultrasonic surface rolling process. International Journal of Fatigue, 2020, 131: 105340.

[127] Q Zhang, Z Hu, W Su, et al. Microstructure and surface properties of 17-4PH stainless steel by ultrasonic surface rolling technology. Surface and Coatings Technology, 2017, 321:64-73.

[128] Y N Petrov, G I Prokopenko, B N Mordyuk, et al. Influence of microstructural modifications induced by ultrasonic impact treatment on hardening and corrosion behavior of wrought Co-Cr-Mo biomedical alloy. Materials Science and Engineering: C, 2016, 58: 1024-1035.

[129] Q Sun, Q Han, S Wang, et al. Microstructure, corrosion behaviour and thermal stability of AA 7150 after ultrasonic shot peening. Surface and Coatings Technology, 2020, 398: 126127.

[130] C Li, M Xu, Z Yu, et al. Electrical discharge-assisted milling for machining titanium alloy. Journal of Materials Processing Technology, 2020, 285: 116785.

[131] H Li, X Yao, S Yan, et al. Analysis of forming defects in electromagnetic incremental forming of a large-size thin-walled ellipsoid surface part of aluminum alloy. Journal of Materials Processing Technology, 2018, 255: 703-715.

[132] D Xu, Z Liao, D Axinte, et al. Investigation of surface integrity in laserassisted machining of nickel based superalloy. Materials \& Design, 2020, 194: 108851.

[133] X Zhang, H Li, M Zhan, et al. Electron force-induced dislocations annihilation and regeneration of a superalloy through electrical in-situ transmission electron microscopy observations. Journal of Materials Science \& Technology, 2020, 36: 79-83.

[134] Y Ye, C Kure, Z Song, et al. Nanocrystallization and enhanced surface mechanical properties of commercial pure titanium by electropulsing-assisted ultrasonic surface rolling. Materials \& Design, 2018, 149: 214-227.

[135] N Li, S Sun, H Bai, et al. Evolution of nano/submicro-scale oxide structures on Ti6Al4V achieved by an ultrasonic shot peening-induction heating approach for high-performance surface design of bone implants. Journal of Alloys and Compounds, 2020, 831:154876. 